\title{
A study on correlation of coronary sinus lactate and troponin T levels with perioperative outcome in patients undergoing cardiac surgery on cardio pulmonary bypass
}

\section{Dr Rupesh Kumar ( $\nabla$ rkctvs@gmail.com )}

Postgraduate Institute of Medical Education \& Research, Chandigarh, India

\section{Dr Vidur Bansal}

Postgraduate Institute of Medical Education \& Research, Chandigarh, India

\section{Dr Subhendu Mahapatra}

Institute of postgraduate medical education \& research, Kolkata

\section{Gautam Sengupta}

Institute of postgraduate medical education\& research, Kolkata.

\section{Research Article}

Keywords: myocardium, cardioplegia, cardiac biomarkers, arrhythmias

Posted Date: September 15th, 2021

DOl: https://doi.org/10.21203/rs.3.rs-902846/v1

License: (c) (i) This work is licensed under a Creative Commons Attribution 4.0 International License.

Read Full License 


\section{Abstract}

Myocardial ischemia is a metabolic phenomenon that occurs in patients undergoing open heart surgery like coronary artery bypass grafting (CABG), valvular heart surgery, vascular surgeries etc., due to stress imposed during cardiopulmonary bypass (CPB), obligatory interruption of coronary blood flow during aortic cross clamp and reperfusion after aortic cross clamp release. The present study is designed to have a detailed study on estimation of coronary sinus lactate and troponin t levels in patients undergoing cardiac surgery with cardiopulmonary bypass and its correlation with various parameters related to the perioperative outcomes.

\section{Introduction}

Myocardial ischemia is a metabolic phenomenon that occurs in patients undergoing open heart surgery like coronary artery bypass grafting (CABG), valvular heart surgery, vascular surgeries etc., due to stress imposed during cardiopulmonary bypass (CPB), obligatory interruption of coronary blood flow during aortic cross clamp and reperfusion after aortic cross clamp release. These effects may manifest as hemodynamic instability, arrhythmias, greater use of inotropes, difficulty in weaning from CPB, use of intra-aortic balloon pump (IABP). The oxygen debt imposed during CPB may herald the onset of postoperative myocardial depression necessitating need for inotropes, prolonged mechanical ventilation, renal/hepatic dysfunction, prolonged intensive care unit (ICU) stay and adds to the morbidity and mortality of patients. In spite of the apparent protective effects of hypothermia and cardioplegia, perioperative myocardial infarction (MI) still occurs frequently during cardiopulmonary bypass and may be difficult to diagnose in less severe cases. ${ }^{1}$ It represents an unsolved problem in the clinical consideration of prognostic implications. ${ }^{2}$ For diagnosis of perioperative myocardial infarction, changes in serum concentrations of creatine kinase and its myocardial-brain isoenzyme (CK-MB) are generally measured along with analysis of the electrocardiogram (ECG) or myocardial scintigraphy. Diagnosis of perioperative $\mathrm{MI}$ on the basis of serum $\mathrm{CK}-\mathrm{MB}$ alone is not always accurate; surgical traumatization of muscle fibres can lead to false-positive results. ${ }^{6}$ The ECG pattern is sometimes difficult to interpret because of bundle branch block or rotation of the heart after the operation, so the presence of a small infarction may not be detected. It is also quite difficult to establish the presence of new infarction in patients who have experienced previous MI. although the ECG lacks sensitivity to all infarctions, it is still useful when changes are noticed that arouse suspicion of altered myocardial status and to monitor progress of an established infarct and treatment of symptomatic arrhythmias. ${ }^{7}$

With the development of a new one-step enzyme immunoassay for cardiac troponin T (TnT), a more cardiac-specific and sensitive method for the detection of perioperative myocardial ischemic injury has become available. ${ }^{9}$ Cardiac TnT is one of the tropomyosin-binding proteins of the regulatory complex located on the thin myofilaments (actin, tropomyosin, and troponin). It differs from skeletal TnT by 6 to 11 amino acid residues and its detection in serum is highly specific as a marker for destruction of cardiac myo-cytes.It is well established that global or regional alterations in the metabolic status of the 
myocardium occur throughout the cross-clamp time and reperfusion, and that the functional recovery of the myocardium is highly dependent on the metabolic status of the heart during these vulnerable periods. [16]

One of the most sensitive markers of inadequate preservation of the myocardium is the development of myocardial tissue acidosis and lactate production. ${ }^{[15]}$ Therefore, the evaluation of myocardial metabolism during cardiac surgery allows the investigator to quantify the degree of physiologic impairment; in particular, direct cannulation of the coronary sinus for coronary sinus blood sampling to measure metabolites or specific biochemical markers of myocardial damage has been shown to be a valid tool to define the degree of such impairment. ${ }^{[17-19]}$ Incomplete myocardial protection is responsible for blood elevation of troponin T. Troponin T is shown to be a specific marker of myocardial injury, with a higher sensitivity and specificity; moreover, recent reports have defined postoperative troponin $\mathrm{T}$ as a sensitive marker of the quality of myocardial protection and of prognostic value for cardiovascular events at follow-up. Similarly, it has been demonstrated that persistent peripheral lactate release during the reperfusion period is an independent predictor of postoperative low output syndrome. ${ }^{[20]}$ Therefore, lactate leakage, as well as the release of troponin T, can define the efficacy of myocardial protection. $[15,19]$ Coronary artery surgery, performed with the aid of cardioplegia, requires a period of cardiac arrest. During this time myocardial ischemia and necrosis may occur. Myocardial injury sustained during coronary artery surgery is an important determinant of functional and clinical outcome. More recently, cardiac troponin $\mathrm{T}$, a component of the tropomyosin contractile regulatory complex, has been shown to be released specifically after myocardial damage ${ }^{24}$ and has been used extensively to assess the effect of interventions and myocardial protection strategies, usually from serialmeasurements in the peripheral venous blood over several days following surgery. ${ }^{[25-28]}$

The present study is designed to have a detailed study on estimation of coronary sinus lactate and troponin $t$ levels in patients undergoing cardiac surgery with cardiopulmonary bypass and its correlation with various parameters related to the perioperative outcomes. This study may guide us regarding the refinement in the myocardial protection procedures and help us in early diagnosis and management of the myocardial insult during cardiac surgery. This study will also help us to quantify the intraoperative release of coronary sinus lactate and troponin $T$ during uncomplicated cardiac surgery and to determine its relation to ischemic time and to recovery of cardiac function and oxidative metabolism.

Tissue perfusion is at risk during cardiac surgery and also in the immediate postoperative period. The development of predictors of death involves evaluating multiple different cardiorespiratory physiologic indices. This approach is often difficult in infants with congenital heart disease (CHD) because of their small size, which limits invasive monitoring capabilities and reliable diagnostic options. Despite these obstacles, the search for predictors to help direct aggressive interventions in this patient population remains an important goal. It is a well-known fact that tissue hypoperfusion is associated with lactic acidosis due to anaerobic metabolism. Measurement of blood lactate levels can hence be used as a marker to assess the adequacy of tissue perfusion. 


\section{Aims And Objectives}

Estimation of coronary sinus lactate and troponin T levels during cardiopulmonary bypass in adult cardiac surgery and its correlation with various parameters related to the postoperative outcomes.

The objectives of the study were:-

1. To estimate the coronary sinus lactate levels in adult patients undergoing cardiac surgery on cardiopulmonary bypass as follows-

a) Pre-CPB ; after removal of aortic cross clamp and after 15 minutes post-CPB

2. To estimate the coronary sinus troponin $\mathrm{T}$ levels adult patients undergoing cardiac surgery on cardiopulmonary bypass as follows-

a) Pre-CPB ;After removal of aortic cross clamp and after 15 minutes post-CPB

3. The intraoperative variables i.e.; the total CPB time and aortic cross clamp time.

4. Electrocardiographic changes, new onset arrhythmias necessitating interventions during ICU stay.

5. Pulmonary function- duration of mechanical ventilation, need for reintubation.

6. Renal function- serum creatinine estimation at various intervals.

7. Duration of ICU and hospital stay.

\section{Materials And Methods}

1. Study area: Institute of Postgraduate Medical Education and Research, SSKM Hospital, Kolkata, West Bengal, India.

2. Study population: All patients of age group 18-65yrs with cardiac surgery on cardiopulmonary bypass attending Outpatients Department of Cardiothoracic and Vascular Surgery, ICVS, Institute of Postgraduate Medical Education \& Research, SSKM Hospital, Kolkata, West Bengal, India.

3. Study period: 1st MARCH 2012 to 31st AUGUST 2013.

4. Sample size: A minimum of 60 patients undergoing cardiac surgery on cardiopulmonary bypass.

5. Sample design:

Inclusion criteria:i) Age Group: 18-65 years. ii) Patients undergoing non-complex cardiac surgery either elective Coronary artery bypass grafting or valvular or adult congenital cardiac diseases.

Exclusion criteria:i)Recent Myocardial infarction $<6$ weeks.ii) Diabetes Mellitus, Concomitant renal or hepatic disorders. iii) Preoperative congestive heart failure, left ventricular ejection fraction $<45 \%$, preoperative hemodynamically unstable arrhythmias, patients undergoing concomitant CABG, congenital and /or valvular surgery. iv) NYHA class IV. 
6. Study design: It is a prospective study.

7. Study tool:

1) Coronary sinus lactate estimation: Nova PHOX Blood Gas Analyzer

2) Coronary sinus Troponin T estimation: The Cobash h 232 cardiac system.

3) Arterial blood gas analysis- Nova PHOX Blood Gas Analyzer

4) IntelliVue MP40 patient monitor:- Electrocardiographic monitoring, heart rate, systolic blood pressure, mean arterial pressure, Central venous pressure measurement.

5) Echocardiogram machine

6) COBE century perfusion pump

8. Study technique:

Patients were recruited from Outpatient Department, Department of CTVS in the division of ICVS at IPGMER, SSKM Hospital, Kolkata fulfilling the study criteria. A consent form was signed by them during recruitment. Detailed history taking and clinical examination was done. Patients were operated and the various parameters were estimated and assessed accordingly.

9. Plan of analysis of data: This is a single centre prospective analysis of patients who underwent cardiac surgery. Baseline data covariable including age,type of presentation, NYHA functional status, surgical approach, cross clamp time, cardiopulmonary time, vasoactive inotropic score, duration of mechanical ventilation, intensive care stays and hospital stays after surgery were summarized as mean and standard deviation. Negative binomial models were assess the baseline data with the other parameters of the study. In case of nonlinear effects of the covariable predictions were transformed with logarithmic and polynomial functions.All statistical calculations were conducted with standard statistical programs (SPSS 8.01, SPSS, Inc., and Chicago, IL).

10. Methodology: All the patients under went cardiac surgery on normothermic cardiopulmonary bypass as per the standard institutional protocol.

\section{Results And Analysis}

Sample Size and Statistical Analysis: Sample Size

Sixty subjects were randomly chosen from the age group of 18-65yrs with cardiac disease necessitating cardiac surgery on cardiopulmonary bypass attending Outpatients Department of Cardiothoracic and Vascular Surgery, ICVS, Institute of Postgraduate Medical Education \& Research, SSKM Hospital, Kolkata, West Bengal, India during the period from 1st March, 2012 to 31st August, 2013 as per the study protocol. 


\section{Statistical Analysis}

Statistical Analysis was performed with help of Epi Info (TM) 3.5.3. EPI INFO is a trademark of the Centers for Disease Control and Prevention (CDC).

Descriptive statistical analysis was performed to calculate the means with corresponding standard deviations (s.d.). Test of proportion was used to find the

Standard Normal Deviate $(Z)$ to compare the difference proportions and chi-square $\left(I^{2}\right)$ test was performed to find the associations. $p \leq 0.05$ was taken to be statistically significant.

The mean age (mean \pm s.d.) of the patients was $36.17 \pm 11.61$ years with range $18-60$ years and the median age was 38.0 years. The mean body surface area (mean \pm s.d.) of the patients was $1.38 \mathrm{~m}^{2}$ with range $1.16-1.62 \mathrm{~m}^{2}$ and the median was $1.38 \mathrm{~m}^{2} .71 .7 \%$ of the patients were with body surface area between $1.25-1.54 \mathrm{~m}^{2}$.

Most of the patients were underwent MVR (33.3\%) followed by ASD Closure (30.0\%) which was not significantly higher than other surgeries $(Z=1.93 ; p>0.05)$. The mean cross clamp time (mean \pm s.d.) of the patients was $70.00 \pm 38.42$ minutes with range $21-166$ minutes and the median was 63.5 minutes. $75.0 \%$ of the patients had cross clamp time within 90 minutes ( 1.5 hours) which was significantly higher than cross clamp time $(Z=7.07 ; p<0.01)$.

The mean cardio pulmonary bypass time (mean \pm s.d.) of the patients was $110.86 \pm 47.33$ minutes with range $50-240$ minutes and the median was 100 minutes.79.90\% of the patients had cardio pulmonary bypass time within 150 minutes which was significantly higher than cardio pulmonary bypass time $(Z=$ $8.31 ; \mathrm{p}<0.01)$.

The mean (mean \pm s.d.) coronary sinus troponin T after cross clamp release of the patients was $440.11 \pm$ $218.77 \mathrm{ng} / \mathrm{L}$ with range $156-1013 \mathrm{ng} / \mathrm{L}$ and the median was $361.5 \mathrm{ng} / \mathrm{L} .75 .0 \%$ of the patients had coronary sinus troponin $T$ level between $150-549 \mathrm{ng} / \mathrm{L}(Z=7.07 ; \mathrm{p}<0.01)$. The mean (mean \pm s.d.) coronary sinus troponin $T$ at 15 minutes after cardio pulmonary bypass of the patients was $696.76 \pm$ $53088 \mathrm{ng} / \mathrm{L}$ with range $104-1986 \mathrm{ng} / \mathrm{L}$ and the median was $566.0 \mathrm{ng} / \mathrm{L} .65 .0 \%$ of the patients were with coronary sinus troponin $\mathrm{T}$ level between $150-549 \mathrm{ng} / \mathrm{L}(Z=7.07 ; \mathrm{p}<0.01)$.

The mean (mean \pm s.d.) coronary sinus pre CPB lactate of the patients was $0.98 \pm 0.20 \mathrm{mmol} / \mathrm{L}$ with range $0.70-1.3 \mathrm{mmol} / \mathrm{L}$ and the median was $0.9 \mathrm{mmol} / \mathrm{L}$. $53.4 \%$ of the patients were with level of coronary sinus lactate $\leq 0.9 \mathrm{mmol} / \mathrm{L}(\mathrm{Z}=0.97 ; \mathrm{p}>0.05)$. The mean (mean $\pm \mathrm{s}$.d.) coronary sinus lactate after cross clamp release of the patients was $6.12 \pm 3.46 \mathrm{mmol} / \mathrm{L}$ with range $2.9-17.3 \mathrm{mmol} / \mathrm{L}$ and the median was $4.6 \mathrm{mmol} / \mathrm{L}$. $68.3 \%$ of the patients were with level of lactate between $2.5-5.5 \mathrm{mmol} / \mathrm{L}(\mathrm{Z}=$ $6.28 ; p<0.01$ ). The mean (mean \pm s.d.) coronary sinus lactate at 15 mins after cardio pulmonary bypass of the patients was $5.03 \pm 4.04 \mathrm{mmol} / \mathrm{L}$ with range $1.9-18.8 \mathrm{mmol} / \mathrm{L}$ and the median was $3.4 \mathrm{mmol} / \mathrm{L}$. 
$68.3 \%$ of the patients were with level of coronary sinus lactate between $1.9-4.0 \mathrm{mmol} / \mathrm{L}(Z=7.07 ; p<$ $0.01)$.

$11.7 \%$ of patients needed intervention for persistent arrhythmia during ICU stay. The mean (mean \pm s.d.) level of pre -operative urea was $22.18 \pm 3.06 \mathrm{mg} / \mathrm{dl}$ with range $17-29 \mathrm{mg} / \mathrm{dl}$ and the median was 22 $\mathrm{mg} / \mathrm{dl} .8 .3 \%$ of the patients had serum urea level more than $45 \mathrm{mg} / \mathrm{dl}$ on the day of ICU discharge. The mean (mean \pm s.d.) duration of mechanical ventilation of the patients was $10.76 \pm 3.18 \mathrm{hrs}$ with range 6 $18 \mathrm{hrs}$ and the median was $10 \mathrm{hrs} .78 .3 \%$ of the patients required mechanical ventilation $12 \mathrm{hrs}$ or less ( $\mathrm{Z}$ $=8.24 ; p<0.01$ ). The mean (mean \pm s.d.) duration of ICU stay of the patients was $88.4 \pm 39.14$ hours with range $48-192$ hours and the median was 72 hours. $75.0 \%$ of the patients required ICU stay 96 hours or less $(Z=7.07 ; p<0.01)$.

As per Pearson Correlation Coefficient, significant positive correlation was found between cross clamp time and level of coronary sinus troponin T after cross clamp release $(r=0.563 ; p<0.01)$, between cross clamp time and level of coronary sinus troponin $T$ at 15 minutes after cardio pulmonary bypass $(r=$ $0.787 ; p<0.01)$, between cross clamp time and level of coronary sinus lactate after cross clamp release ( $r$ $=0.738 ; p<0.01)$, between cross clamp time and level of coronary sinus lactate at 15 minutes after cardio pulmonary bypass $(r=0.768 ; p<0.01)$, between cross clamp time and level of urea on the day of ICU discharge $(r=0.379 ; p<0.01)$, between cross clamp time and level of creatinine on the day of ICU discharge $(r=0.278 ; p<0.01)$, between cross clamp time and duration of mechanical ventilation $(r=$ $0.821 ; p<0.01)$, between cross clamp time and duration of ICU stay $(r=0.839 ; p<0.01)$ and between cross clamp time and duration of hospital stay $(r=0.864 ; p<0.01)$.

As per Spearman's rho for nonparametric values significant positive correlation was found between cross clamp time and arrhythmia $(r=0.459 ; p<0.01)$.

As per Pearson Correlation Coefficient significant positive correlation was found between cardio pulmonary bypass time and level of coronary sinus troponin $T$ after cross clamp release $(r=0.782 ; p<$ $0.01)$, between cardio pulmonary bypass time and level of coronary sinus troponin $T$ at 15 minutes after cardio pulmonary bypass $(r=0.678 ; p<0.01)$, between cardio pulmonary bypass time and level of coronary sinus lactate after cross clamp release $(r=0.767 ; p<0.01)$, between cardio pulmonary bypass time and level of coronary sinus lactate at 15 minutes after cardio pulmonary bypass $(r=0.766 ; p<0.01)$, between cardio pulmonary bypass time and level of urea on the day of ICU discharge $(r=0.352 ; p<0.01)$, between cardio pulmonary bypass time and level of creatinine on the day of ICU discharge $(r=0.274 ; p<$ $0.01)$, between cardio pulmonary bypass time and duration of mechanical ventilation $(r=0.62 ; p<0.01)$, between cardio pulmonary bypass time and duration of ICU stay $(r=0.806 ; p<0.01)$ and between cardio pulmonary bypass time and duration of hospital stay $(r=0.806 ; p<0.01)$.

As per Spearman's rho for nonparametric values significant positive correlation was found between cardio pulmonary bypass time and arrhythmia $(r=0.426 ; p<0.01)$. 
Seven out of sixty patients suffered from arrhythmias needing some form of intervention to treat arrhythmia, either with pacing, pacemaker or medical therapy during the whole ICU stay.

These group of patients had a significantly high mean cross clamp time $(121.85 \pm 25.64$ minutes $)$ and mean cardiopulmonary bypass time ( $169.42 \pm 45.91$ minutes $)$, a significantly high level of mean coronary sinus troponin T after cross clamp release $(672.42 \pm 210.51 \mathrm{ng} / \mathrm{L}$ ) and coronary sinus troponin $T$ at 15 minutes after cardio pulmonary bypass $(1569.28 \pm 452.89 \mathrm{ng} / \mathrm{L})$. Level of coronary sinus lactate after cross clamp release $(12.37 \pm 3.85 \mathrm{mmol} / \mathrm{l})$ and level of coronary sinus lactate at 15 minutes after cardio pulmonary bypass $(13.48 \pm 4.31 \mathrm{mmol} / \mathrm{l})$ was also significantly high. Level of urea on the day of ICU discharge was also significantly high $(49.00 \pm 10.72 \mathrm{mg} / \mathrm{dl})$. Mean ICU stay was delayed by upto $137.14 \pm 11.71$ hours and mean hospital stay after operation was $15.14 \pm 1.06$ days. Level of creatinine on the day of ICU discharge was also high $(1.85 \pm 0.96 \mathrm{mg} / \mathrm{dl})$ when compared with the patients who had not suffered any arrhythmias needing intervention in ICU.

None of the patients operated for atrial septal defect, isolated aortic valve disease or left atrial myxomas had an arrhythmia needing intervention in ICU, whereas four patients needing double valve replacement and three patients of mitral valve replacement suffered from arrhythmias necessitating intervention. As per Spearman's rho for nonparametric values significant positive correlation was found between coronary sinus troponin $T$ after cross clamp release and arrhythmia $(r=0.357 ; p<0.01)$. As per Pearson Correlation Coefficient significant positive correlation was found between coronary sinus troponin $T$ after cross clamp release and cross clamp time. $(r=0.563 ; p<0.01)$, and cardio pulmonary bypass time $(r=0.571 ; p$ $<0.01)$, and level of coronary sinus troponin $T$ at 15 minutes after cardio pulmonary bypass $(r=0.846 ; p<$ $0.01)$, and level of coronary sinus lactate after cross clamp release $(r=0.740 ; p<0.01)$, and level of coronary sinus lactate at 15 minutes after cardio pulmonary bypass $(r=0.690 ; p<0.01)$, and mechanical ventilation tine $(r=0.620 ; p<0.01)$, and duration of ICU stay $(r=0.595 ; p<0.01)$, and level of urea on the day of ICU discharge $(r=0.300 ; p<0.02)$, and duration of hospital stay $(r=0.575 ; p<0.01)$.

As per Spearman's rho for nonparametric values significant positive correlation was found between coronary sinus troponin $\mathrm{T}$ at 15 minutes after cardio pulmonary bypass and arrhythmia $(r=0.766 ; p<$ 0.01).

As per Pearson Correlation Coefficient significant positive correlation was found between coronary sinus troponin $T$ at 15 minutes after cardio pulmonary bypass and cross clamp time $(r=0.787 ; p<0.01)$, and cardio pulmonary bypass time $(r=0.782 ; p<0.01)$, and level of coronary sinus troponin $T$ after cross clamp release $(r=0.846 ; p<0.01)$, and level of coronary sinus lactate after cross clamp release $(r=0.876$; $p<0.01)$, and level of coronary sinus lactate at 15 minutes after cardio pulmonary bypass $(r=0.873 ; p<$ $0.01)$, and mechanical ventilation tine $(r=0.738 ; p<0.01)$, and duration of ICU stay $(r=0.755 ; p<0.01)$, and level of urea on the day of ICU discharge $(r=0.467 ; p<0.01)$, and duration of hospital stay $(r=0.766$; $p<0.01)$. As per Spearman's rho for nonparametric values significant positive correlation was found between level of coronary sinus lactate after cross clamp release and arrhythmia $(r=0.500 ; p<0.01)$. As per Pearson Correlation Coefficient significant positive correlation was found between level of coronary 
sinus lactate after cross clamp release and cross clamp time $(r=0.738 ; p<0.01)$, and cardio pulmonary bypass time $(r=0.746 ; p<0.01)$, and level of coronary sinus troponin $T$ after cross clamp release $(r=$ $0.740 ; p<0.01)$, and Level of coronary sinus troponin $T$ at 15 minutes after cardio pulmonary bypass $(r=$ $0.876 ; p<0.01)$, and level of coronary sinus lactate at 15 minutes after cardio pulmonary bypass $(r=$ $0.949 ; p<0.01)$, and mechanical ventilation tine $(r=0.676 ; p<0.01)$, and duration of ICU stay $(r=0.771 ; p$ $<0.01)$, and level of urea on the day of ICU discharge $(r=0.538 ; p<0.01)$, and duration of hospital stay $(r=$ $0.769 ; p<0.01)$. As per Spearman's rho for nonparametric values significant positive correlation was found between level of coronary sinus lactate at 15 minutes after cardio pulmonary bypass and arrhythmia $(r=0.521 ; p<0.01)$. As per Pearson Correlation Coefficient significant positive correlation was found between level of coronary sinus lactate level of lactate at 15 minutes after cardio pulmonary bypass and cross clamp time $(r=0.768 ; p<0.01)$, and cardio pulmonary bypass time $(r=0.767 ; p<0.01)$, and level of coronary sinus troponin $T$ after cross clamp release $(r=0.693 ; p<0.01)$, and level of coronary sinus troponin $T$ at 15 minutes after cardio pulmonary bypass $(r=0.873 ; p<0.01)$, and level of coronary sinus lactate after cross clamp release $(r=0.949 ; p<0.01)$, and mechanical ventilation tine $(r=0.696 ; p<$ $0.01)$, and duration of ICU stay $(r=0.752 ; p<0.01)$, and level of urea on the day of ICU discharge $(r=0.611$; $p<0.01)$, and duration of hospital stay $(r=0.805 ; p<0.01)$.

\section{Discussion}

In this study we have done estimation of troponin T and lactate through coronary sinus with the help of retrograde cardioplegia cannula in adult patients undergoing cardiac surgery before going to cardiopulmonary bypass, after aortic cross clamp release and 15 minutes after weaning from cardiopulmonary bypass and have correlated these values with perioperative outcomes and have tried to draw a correlation of coronary sinus lactate and troponin t levels with perioperative outcome in patients undergoing cardiac surgery on cardio pulmonary bypass. .Rao et al concluded that persistent lactate release during reperfusion suggests a delayed recovery of aerobic myocardial metabolism and may be related to intraoperative misadventure or inadequate myocardial protection. Myocardial lactate release may be useful as an alternative end-point in clinical trials evaluating perioperative myocardial protection. ${ }^{31}$ Our study do convey the similar inference like the mean (mean \pm s.d.) estimate of coronary sinus lactate after cross clamp release of the patients was $6.12 \pm 3.46 \mathrm{mmol} / \mathrm{L}$ with range $2.9-17.3$ $\mathrm{mmol} / \mathrm{L}$ and the median was $4.6 \mathrm{mmol} / \mathrm{L}$. $68.3 \%$ of the patients had coronary sinus lactatebetween $2.5-$ $5.5 \mathrm{mmol} / \mathrm{L}(Z=6.28 ; p<0.01)$. All of the patients had more than normal level of coronary sinus lactate after aortic cross clamp release. Also the mean (mean \pm s.d.) estimate of coronary sinus lactate at 15 minutes after cardio pulmonary bypass of the patients was $5.03 \pm 4.04 \mathrm{mmol} / \mathrm{L}$ with range $1.9-18.8$ $\mathrm{mmol} / \mathrm{L}$ and the median was $3.4 \mathrm{mmol} / \mathrm{L}$. $61.7 \%$ of the patients had a higher than normal level of coronary sinus lactate i.e.; $>2.5 \mathrm{mmol} / \mathrm{L}(Z=7.07 ; p<0.01) .11 .7 \%$ of patients needed intervention for persistent new arrhythmia during ICU stay. The mode of treatment was either pacing, pacemaker or medical therapy. The level of serum urea rose by its normal limit ( $>45 \mathrm{mg} / \mathrm{dl}$ ) in $8.3 \%$ of the patients on the day of ICU discharge. Theoverall level of serum creatinine remained minimally deranged by the effect of surgery in these group of patents by its normal limit $(0.7-1.4 \mathrm{mg} / \mathrm{dl})$ in $8.3 \%$ of the patients on the day 
of ICU discharge. The mean (mean \pm s.d.) level of pre-operative creatinine of the patients was $0.88 \pm 0.16$ $\mathrm{mmol} / \mathrm{L}$ with range $0.6-1.1 \mathrm{mmol} / \mathrm{L}$ and the median was $0.9 \mathrm{mmol} / \mathrm{L}$. The mean (mean $\pm \mathrm{s} . \mathrm{d}$.) level of creatinine on the day of ICU discharge of the patients was $1.04 \pm 0.48 \mathrm{mmol} / \mathrm{L}$ with range $0.6-3.3$ $\mathrm{mmol} / \mathrm{L}$ and the median was $0.9 \mathrm{mmol} / \mathrm{L}$. However one patient undergoing double valve replacement for a combined disease of mitral stenosis and aortic regurgitation had a high postoperative serum creatinine value of $2.8 \mathrm{mg} / \mathrm{dl}$ and required hemodialysis. This patient had a high aortic cross clamp time, cardiopulmonary bypass time and a very high coronary sinus troponin $\mathrm{T}$ as well as lactate values during this period. This patient also required high inotropes and had suffered ventricular tachycardia immediately after operation which was reverted back with external cardiac defibrillator. The mean (mean \pm s.d.) duration of mechanical ventilation of the patients was $10.76 \pm 3.18 \mathrm{hrs}$ with range $6-18 \mathrm{hrs}$ and the median was $10 \mathrm{hrs} .78 .3 \%$ of the patients required mechanical ventilation $12 \mathrm{hrs}$ or less $(\mathrm{Z}=8.24$; $<$ 0.01). The mean (mean \pm s.d.) duration of ICU s tay of the patients was $88.4 \pm 39.14$ hours with range 48-192 hours and the median was 72 hours. $75.0 \%$ of the patients required ICU stay 96 hours or less ( $Z$ $=7.07 ; p<0.01$ ). The mean (mean \pm s.d.) duration of hospital stay of the patients was $10.85 \pm 2.47$ days wit $h$ range $9-17$ days and the median was 10 days. $25.0 \%$ of the patients got discharged from the hospital after 12 days of operation $(Z=7.07 ; p<0.01)$. As per Pearson Correlation Coefficient, significant positive correlation was found betweencross clamp time and level of coronary sinus troponin $T$ after cross clamp release $(r=0.563 ; p<0.01)$, between cross clamp time and level of coronary sinus troponin $T$ at 15 minutes after cardio pulmonary bypass $(r=0.787 ; p<0.01)$, between cross clamp time and level of coronary sinus lactate after cross clamp release $(r=0.738 ; p<0.01)$, between cross clamp time and level of coronary sinus lactate at 15 minutes after cardio pulmonary bypass $(r=0.768 ; p<0.01)$, between cross clamp time and level of urea on the day of ICU discharge $(r=0.379 ; p<0.01)$, between cross clamp time and level of creatinine on the day of ICU discharge $(r=0.278 ; p<0.01)$, between cross clamp time and duration of mechanical ventilation $(r=0.821 ; p<0.01)$, between cross clamp time and duration of ICU stay $(r=0.839 ; p<0.01)$ and between cross clamp time and duration of hospital stay $(r=0.864 ; p<0.01)$. As per Spearman's rho for nonparametric values significant positive correlation was found between cross clamp time and arrhythmia $(r=0.459 ; p<0.01)$.

As per Pearson Correlation Coefficient, significant positive correlation was found between cardio pulmonary bypass time and level of coronary sinus Troponin T after cross clamp release $(r=0.782 ; p<$ 0.01), between cardio pulmonary bypass time and level of coronary sinus Troponin $T$ at 15 minutes after cardio pulmonary bypass $(r=0.678 ; p<0.01)$, between cardio pulmonary bypass time and level of coronary sinus lactate after cross clamp release $(r=0.767 ; p<0.01)$, between cardio pulmonary bypass time and level of lactate at 15 minutes after cardio pulmonary bypass $(r=0.766 ; p<0.01)$, between cardio pulmonary bypass time and level of urea on the day of ICU discharge $(r=0.352 ; p<0.01)$, between cardio pulmonary bypass time and level of creatinine on the day of ICU discharge $(r=0.274 ; p<0.01)$, between

cardio pulmonary bypass time and duration of mechanical ventilation $(r=0.62 ; p<0.01)$, between cardio pulmonary bypass time and duration of ICU stay $(r=0.806 ; p<0.01)$ and between cardio pulmonary bypass time and duration of hospital stay $(r=0.806 ; p<0.01)$. As per Spearman's rho for nonparametric values significant positive correlation was found between cardio pulmonary bypass time and arrhythmia 
$(r=0.426 ; p<0.01)$. Romeroa et al, in their study included 100 patients with predominantly aortic valve ( $n$ $=42)$ or ischemic heart $(n=58)$ diseases. Twenty-nine patients $(29 \%)$ developed post-surgical AF. Patients developing AF had a longer hospital stay $(P=0.005)$. hsTnT levels increased after surgery $[P<0.001]$, indicating perioperative myocardial injury, with higher presurgery levels in patients who developed $A F[P=$ 0.015]. In our studyseven out of sixty patients suffered from arrhythmias needing some form of intervention to treat arrhythmia, either with pacing, pacemaker or medical therapy during the whole ICU stay.These group of patients had a significantly high mean cross clamp time (121.85 $\pm 25.64 \mathrm{~min}$ utes) and mean cardiopulmonary bypass time (169.42 \pm 45.91 minutes ), a significantly high level of mean coronary sinus troponin T after cross clamp release $(672.42 \pm 210.51 \mathrm{ng} / \mathrm{L})$ and coronary sinus troponin $\mathrm{T}$ at 15 minutes after cardio pulmonary bypass $(1569.28 \pm 452.89 \mathrm{ng} / \mathrm{L})$. Level of coronary sinus lactate after cross clamp release $(12.37 \pm 3.85 \mathrm{mmol} / \mathrm{dl})$ and level of coronary sinus lactate at 15 minutes after cardio pulmonary bypass $(13.48 \pm 4.31 \mathrm{mmol} / \mathrm{dl})$ was also significantly high. Level of urea on the day of ICU discharge was also significantly high $(49.00 \pm 10.72)$. Mean ICU stay was delayed by up to $137.14 \pm$ 11.71hours and mean hospital stay after operation was $15.14 \pm 1.06$ Level of creatinine on the day of ICU discharge was also high $(1.85 \pm 0.96)$ was compared to patients who had not suffered any arrhythmias needing intervention in ICU. None of the patients operated for atrial septal defect, isolated aortic valve disease or left atrial myxomas in our study group had an arrhythmia needing intervention in ICU, whereas four patients needing double valve replacementand three patients of mitral valve replacement suffered from arrhythmias necessitating intervention. Januzzi et al, in their study for assessment of serum TnT inferred that TnT adds a powerful prognostic information regarding the impending development of severe postoperative complications, including death, as well as adding confirmatory information in patients with unexplained postoperative hemodynamic instability.

A meta-analysis done byBuse et al on the prognostic value of troponin release after adult cardiac surgery to assess the accuracy of increased troponin $(\mathrm{Tn})$ concentrations for the prediction of mid-term (12 months) mortality after coronary artery bypass graft (CABG) and valve surgery. In our study as per Spearman's rho for nonparametric values significant positive correlation was found between Troponin $T$ after cross clamp release and arrhythmia $(r=0.357 ; p<0.01)$.As per Pearson Correlation Coefficient significant positive correlation was found between Troponin $T$ after cross clamp release and cross clamp time $(r=0.563 ; p<0.01)$, and cardio pulmonary bypass time $(r=0.571 ; p<0.01)$, and level of Troponin T at 15 minutes after cardio pulmonary bypass $(r=0.846 ; p<0.01)$, and level of lactate after cross clamp release $(r=0.740 ; p<0.01)$, and level of lactate at 15 minutes after cardio pulmonary bypass $(r=0.690 ; p$ $<0.01)$, and mechanical ventilation tine $(r=0.620 ; p<0.01)$, and duration of ICU stay $(r=0.595 ; p<0.01)$, and level of urea on the day of ICU discharge $(r=0.300 ; p<0.02)$, and duration of hospital stay $(r=0.575$; $p<0.01)$. .As per Spearman's rho for nonparametric values significant positive correlation was found between Troponin $T$ at 15 minutes after cardio pulmonary bypass and arrhythmia $(r=0.766 ; p<0.01)$. As per Pearson Correlation Coefficient significant positive correlation was found between Troponin $\mathrm{T}$ at 15 minutes after cardio pulmonary bypass and cross clamp time $(r=0.787 ; p<0.01)$, and cardio pulmonary bypass time $(r=0.782 ; p<0.01)$, and level of Troponin T after cross clamp release $(r=0.846 ; p<0.01)$, and level of lactate after cross clamp release $(r=0.876 ; p<0.01)$, and level of lactate at 15 minutes after 
cardio pulmonary bypass $(r=0.873 ; p<0.01)$, and mechanical ventilation tine $(r=0.738 ; p<0.01)$, and duration of ICU stay $(r=0.755 ; p<0.01)$, and level of urea on the day of ICU discharge $(r=0.467 ; p<0.01)$, and duration of hospital stay $(r=0.766 ; p<0.01)$.Troponin I and lactate from coronary sinus predicting cardiac complications after myocardial revascularization is a well-documented feature as studied by Francesco et al. Troponin I and lactate were sampled preoperatively and intraoperatively from the coronary sinus, and at 12, 24, 48, and 72 hours. Hospital outcome was recorded. Receiver operating curves for coronary sinus troponin I and lactate were constructed to differentiate patients with or without $\mathrm{AMI}$ and myocardial damage. Acute myocardial infarction developed in 6 patients (3.2\%), with higher troponin I and lactate at all-time points $(p<0.05)$, longer intubation time $(p=0.003)$, intensive care unit stay $(p=0.001)$, hospital stay $(p=0.001)$, higher atrial fibrillation $(p=0.001)$, and worse ventricular function ( $p=0.001)$. Myocardial damage developed in 6 patients $(3.2 \%)$, showing higher troponin I at alltime points $(p<0.001)$, higher intraoperative lactate $(p=0.04)$, longer intubation time $(p=0.005)$, and intensive care unit stay $(p=0.03)$. In our study as per Spearman's rho for nonparametric values significant positive correlation was found between level of coronary sinus lactate after cross clamp release and arrhythmia $(r=0.500 ; p<0.01)$. As per Pearson Correlation Coefficient significant positive correlation was found between level ofcoronary sinus lactate after cross clamp release and cross clamp time $(r=0.738 ; p$ $<0.01)$, and cardio pulmonary bypass time $(r=0.746 ; p<0.01)$, and level ofcoronary sinus troponin $T$ after cross clamp release $(r=0.740 ; p<0.01)$, and level of coronary sinus troponin $T$ at 15 minutes after cardio pulmonary bypass $(r=0.876 ; p<0.01)$, and level of coronary sinus lactate at 15 minutes after cardio pulmonary bypass $(r=0.949 ; p<0.01)$, and mechanical ventilation tine $(r=0.676 ; p<0.01)$, and duration of ICU stay $(r=0.771 ; p<0.01)$, and level of urea on the day of ICU discharge $(r=0.538 ; p<0.01)$, and duration of hospital stay $(r=0.769 ; p<0.01)$. Borowski et al studied on the metabolic monitoring of post ischemic myocardium during intermittent warm blood cardioplegia administration and concluded that it was not the degree of lactate washout, but the lactate concentration at the end of each reperfusion, that correlated significantly with global metabolic recovery time, which suggests the importance of effective reperfusion. ${ }^{43}$ In our study we noted that as per Spearman's rho for nonparametric values significant positive correlation was found between level of lactate level of lactate at 15 minutes after cardio pulmonary bypassand arrhythmia $(r=0.521 ; p<0.01)$. As per Pearson Correlation Coefficient significant positive correlation was found between level ofcoronary sinus lactate at 15 minutes after cardio pulmonary bypass and cross clamp time $(r=0.768 ; p<0.01)$, and cardio pulmonary bypass time $(r$ $=0.767 ; p<0.01)$, and level of coronary sinus troponin $T$ after cross clamp release $(r=0.693 ; p<0.01)$, and Level of coronary sinus troponin T at 15 minutes after cardio pulmonary bypass $(r=0.873 ; p<0.01)$, and level ofcoronary sinus lactate after cross clamp release $(r=0.949 ; p<0.01)$, and mechanical ventilation tine $(r=0.696 ; p<0.01)$, and duration of ICU stay $(r=0.752 ; p<0.01)$, and level of urea on the day of ICU discharge $(r=0.611 ; p<0.01)$, and duration of hospital stay $(r=0.805 ; p<0.01)$. Analyzing the patients who underwent pericardial patch closure of atrial septal defect we found that the mean cross clamp time (in minutes) was $32.66 \pm 8.75$, withrange from $21-56$ minutes and median of 34 minutes. The mean cardiopulmonary Bypass time (in minutes) was 73.55 \pm 17.31 , rangeof $50-109$ and median value of 69.5 minutes. The mean Level of Troponin T after cross clamp release $(\mathrm{ng} / \mathrm{L})$ was found as $319.11 \pm$ 128.60 with range of $156-630 \mathrm{ng} / \mathrm{L}$ and median of $319 \mathrm{ng} / \mathrm{L}$. The mean level of coronary sinus troponin $\mathrm{T}$ 
at 15 minutes after cardio pulmonary bypass $(\mathrm{ng} / \mathrm{L})$ was $289.77 \pm 260.79$ with range of $104-1002$ and a median value of 165 . The level of coronary sinus lactate before going to cardiopulmonary bypass was $0.98 \pm 0.19 \mathrm{mmol} / \mathrm{L}$ with a range of $0.7-1.3 \mathrm{mmol} / \mathrm{L}$ and a median of $0.9 \mathrm{mmol} / \mathrm{L}$. The mean level of lactate after cross clamp release $(\mathrm{mmol} / \mathrm{L}) 4.10 \pm 0.82$ range $2.9-6.5$ with median of $3.95 \mathrm{mmol} / \mathrm{L}$.Level of lactateat 15 minutes after cardio pulmonary bypass $(\mathrm{mmol} / \mathrm{L}) 2.32 \pm 0.29 \mathrm{mmol} / \mathrm{L}$ and range of 1.9 3.0 and median of $2.3 \mathrm{mmol} / \mathrm{L}$. The mean Mechanical ventilation (in hours) was $8.16 \pm 2.00$ with a range of $6-12$ and median of 8 hours. The mean duration of ICU stay (in hours)was $54.66 \pm 11.06$ with range of 48-72 hoursand median of 48 hours. The meanduration of hospital stay (in days) was $9.11 \pm 0.32$ with a range of 9-10 days and median stay of 9 days.

.Piekarska et al in their study found that the serum concentration of cTnT after AVR increased significantly compared to the preoperative value. There was a significant positive correlations between aortic cross-clamp time $(r=0.23, p=0.04)$, cardiopulmonary bypass time $(r=0.4, p=0.00029)$, duration of the surgery $(r=0.30, p=0.008)$, and postoperative $c \operatorname{TnT}$ level. Three ( $4 \%)$ patients required IABP support, 37 (46\%) patients required inotropic support, and 11 (14\%) patients had a prolonged ICU stay (>48 h). Thirty eight (48\%) patients required either inotropic support or IABP insertion. At least one adverse event occurred in $44(56 \%)$ patients. Median postoperative serum cTnT concentration was $0.31 \mathrm{ng} / \mathrm{mL}$ (interquartile range $0.23-0.60 \mathrm{ng} / \mathrm{mL}$ ). They however failed to find a statistically significant difference in postoperative cTnT level between patients with and without adverse events. ${ }^{33}$ Whereas in our study of patients who underwent aortic valve replacement for an isolated aortic valve disease, we found that the mean cross clamp time (in minutes) was $70.11 \pm 9.37$, withrange from $56-80$ minutes and median of 74 minutes. The mean cardiopulmonary bypass time (in minutes) was $108.55 \pm 14.90$, rangeof 92-136 min and median value of 100 minutes. The mean level of coronary sinus troponin $T$ after cross clamp release ( $\mathrm{ng} / \mathrm{L}$ ) was found as $334.88 \pm 213.21$ with range of $159-843$ and median of $296 \mathrm{ng} / \mathrm{L}$. The mean level of Troponin $T$ at 15 minutes after cardio pulmonary bypass was $532.33 \pm 219.35 \mathrm{ng} / \mathrm{l}$ with range of $304-$ $1026 \mathrm{ng} / \mathrm{L}$ and a median value of $488 \mathrm{ng} / \mathrm{L}$. The level of coronary sinus lactate before going to cardiopulmonary bypass was $0.92 \pm 0.24 \mathrm{mmol} / \mathrm{L}$ with a range of $0.7-1.0 \mathrm{mmol} / \mathrm{L}$ and a median of $0.9 \mathrm{mmol} / \mathrm{L}$. The mean level of lactate after cross clamp release $(\mathrm{mmol} / \mathrm{L}) 5.15 \pm 1.58$ range 3.7-9.1 $\mathrm{mmol} / \mathrm{Lw}$ ith median of $4.6 \mathrm{mmol} / \mathrm{L}$.Level of lactate at 15 minutes after cardio pulmonary bypass $(\mathrm{mmol} / \mathrm{L}) 4.15 \pm 1.62 \mathrm{mmol} / \mathrm{L}$ and range of $2.3-7.3$ and median of $3.8 \mathrm{mmol} / \mathrm{L}$. The mean mechanical ventilation (in hours) was $10.22 \pm 1.64$ with a range of $8-12$ hoursand median of 10 hours. The mean Duration of ICU stay (in hours) was $88.0 \pm 12$.0with range of $72-96$ hoursand median of 96hours. The mean duration of hospital stay (in days) was $9.77 \pm 0.66$ with a range of 9-10 days and median stay of 10 days.Cross clamping the aorta in cardiac surgery on cardioplegic arrested heart has led to significant myocardial compromise in mitral valve surgery as documented by Morfa et al. We analyzed our patients who underwent mitral valve replacement for an isolated mitral valve disease, we found that the mean Cross clamp time (in minutes) was $68.4 \pm 20.59$, withrange from 38-103 minutes and median of 68 minutes. The mean Cardiopulmonary Bypass time (in minutes) was $101.1 \pm 24.53$, rangeof $65-128$ minutes and median value of 105.5 minutes. The mean Level of Troponin $T$ after cross clamp release (ng/L) was found as $437.7 \pm 174.27$ with range of $186-832$ and median of $361.5 \mathrm{ng} / \mathrm{L}$. The mean level of 
Troponin $\mathrm{T}$ at 15 minutes after cardio pulmonary bypass $(\mathrm{ng} / \mathrm{L})$ was $699.45 \pm 313.67$ with range of 286 $-1643 \mathrm{ng} / \mathrm{L}$ and a median value of $595 \mathrm{ng} / \mathrm{L}$. The level of coronary sinus lactate before going to cardiopulmonary bypass was $1.01 \pm 0.03 \mathrm{mmol} / \mathrm{L}$ with a range of $0.7-1.3 \mathrm{mmol} / \mathrm{L}$ and a median of $0.95 \mathrm{mmol} / \mathrm{L}$. The mean level of lactate after cross clamp release $(\mathrm{mmol} / \mathrm{L}) 5.17 \pm 1.81$ range 3.6 $-10.6 \mathrm{mmol} / \mathrm{Lw}$ ith median of $4.6 \mathrm{mmol} / \mathrm{L}$.Level of lactate at 15 minutes after cardio pulmonary bypass $(\mathrm{mmol} / \mathrm{L}) 4.38 \pm 2.43 \mathrm{mmol} / \mathrm{L}$ and range of $2.3-11.4 \mathrm{mmol} / \mathrm{L}$ and median of $3.8 \mathrm{mmol} / \mathrm{L}$. The mean Mechanical ventilation (in hours) was $10.9 \pm 2.59$ wth a range of $6-16$ hoursand median of 11 hours. The mean Duration of ICU stay (in hours) was $85.2 \pm 27.50$. with range of $48-144$ hours and median of 72 hours. The mean Duration of hospital stay (in days) was $10.8 \pm 2.01$ with a range of 9-16 days and median stay of 10 days. Analyzing the patients who underwent double valve replacement for a mixed mitral and aortic valve disease, we found that the mean cross clamp time (in minutes) was $134.09 \pm$ 925.74, withrange from $69-166$ minutes and median of 139 minutes. The mean cardiopulmonary bypass time (in minutes) was $194.63 \pm 30.19$, range of $120-240$ minutes and median value of 196 minutes. The mean level of coronary sinus troponin T after cross clamp release $(\mathrm{ng} / \mathrm{L})$ was found as $724.45 \pm 186.64$ $\mathrm{ng} / \mathrm{l}$ with range of $402-1013 \mathrm{ng} / \mathrm{L}$ and median of $746 \mathrm{ng} / \mathrm{L}$. The mean level of coronary sinus troponin $\mathrm{T}$ at 15 minutes after cardio pulmonary bypass was $1569.00 \pm 356.23 \mathrm{ng} / \mathrm{L}$ with rang e of 1014-1986 $\mathrm{ng} / \mathrm{Land}$ a median value of $1555 \mathrm{ng} / \mathrm{L}$. The level of coronary sinus lactate before going to cardiopulmonary bypass was $1.01 \pm 0.19 \mathrm{mmol} / \mathrm{L}$ with a range of $0.7-1.3 \mathrm{mmol} / \mathrm{L}$ and a median of 1.0 $\mathrm{mmol} / \mathrm{L}$. The mean level of lactate after cross clamp release $(\mathrm{mmol} / \mathrm{L}) 12.19 \pm 3.24$ range $7.4-$ $17.3 \mathrm{mmol} /$ Lwith median of $12.9 \mathrm{~mol} / \mathrm{L}$.Level of lactate at $15 \mathrm{minutes}$

after cardio pulmonary bypass $(\mathrm{mmol} / \mathrm{L}) 11.70 \pm 4.25 \mathrm{mmol} / \mathrm{L}$ and range of $7.0-18.8 \mathrm{mmol} / \mathrm{L}$ median of $10.4 \mathrm{mmol} / \mathrm{L}$. The mean Mechanical ventilation (in hours) was $15.3 \pm 1.5 \mathrm{wth}$ a range of $12-18$ hoursand median of 16 hours. The mean Duration of ICU stay (in hours) was $152.72 \pm 22.18$ with range of 120-192 hours and median of 144 hours. The mean Duration of hospital stay (in days) was $14.18 \pm$ 1.88 with a range of 10-17days and median stay of 15 days..Analyzing the patients who underwent excision of left atrial myxomas for, we found that the mean cross clamp time (in minutes) was $69.00 \pm$ 8.48 , with range from $63-75$ minutes and median of 69 minutes. The mean cardiopulmonary bypass time (in minutes) was $94.00 \pm 1.41$, rangeof $93-95$ and median value of 94 minutes. The mean Level of coronary sinus troponin $\mathrm{T}$ after cross clamp release (ng/L) was found as $463.00 \pm 4.24$ with range of $460-466$ and median of $463 \mathrm{ng} / \mathrm{L}$. The mean level of coronary sinustroponin $\mathrm{T}$ at 15 minutes after cardio pulmonary bypass ( $\mathrm{ng} / \mathrm{L}$ ) was $275.50 \pm 17.67$ with range of $263-288 \mathrm{ng} / \mathrm{L}$ and a median value of 275 $\mathrm{ng} / \mathrm{L}$. The level of coronary sinus lactate before going to cardiopulmonary bypass was $0.80 \pm 0.14$ $\mathrm{mmol} / \mathrm{L}$ with a range of $0.7-0.9 \mathrm{mmol} / \mathrm{L}$ and a median of $0.8 \mathrm{mmol} / \mathrm{L}$. The mean level of coronary sinuslactate after cross clamp release $(\mathrm{mmol} / \mathrm{L}) 4.70 \pm 0.14$ range $4.6-4.8 \mathrm{mmol} / \mathrm{Lw}$ ith median of $4.7 \mathrm{mmol} / \mathrm{L}$. Thelevel of coronary sinuslactate at 15 minutes after cardio pulmonary bypass $(\mathrm{mmol} / \mathrm{L})$ was $3.00 \pm 0.56 \mathrm{mmol} / \mathrm{L}$ and range of $2.6-3.4$ and median of $3.0 \mathrm{mmol} / \mathrm{L}$. The mean mechanical ventilation (in hours) was 10.00 with a range of 10-10 hoursand median of 10 hours. The mean duration of ICU stay (in hours) was $72.0 \pm 33.94$ with range of 48 -96hoursand median of 72 hours. The mean 
duration of hospital stay (in days) was $10.00 \pm 1.41$ with a range of $9-11$ days and median stay of 10 days.

\section{Conclusion}

Having completed the result, analysis and the discussion on major issues, we finally present the following observations to arrive at a conclusion: Patients suffer with some extent of myocardial injury due to cross clamping the aorta with cardioplegic arrest for a cardiac surgery as evidenced by more than normal level of coronary sinus lactate after aortic cross clamp release. There is a significant positive correlation between cross clamp time and level of coronary sinus troponin T after cross clamp release, between cross clamp time and level of coronary sinus troponin $\mathrm{T}$ at 15 minutes after cardio pulmonary bypass, between cross clamp time and level of coronary sinus lactate after cross clamp release, between cross clamp time and level of coronary sinus lactate at 15 minutes after cardio pulmonary bypass, between cross clamp time and level of urea on the day of ICU discharge, between cross clamp time and level of creatinine on the day of ICU discharge, between cross clamp time and duration of mechanical ventilation, between cross clamp time and duration of ICU stay and between cross clamp time and duration of hospital stay. A significant positive correlation is also noted between cross clamp time and arrhythmia needing intervention in the ICU. A significant positive correlation is also concluded between cardio pulmonary bypass time and level of coronary sinus troponin $\mathrm{T}$ after cross clamp release, between cardio pulmonary bypass time and level of coronary sinus troponin $T$ at 15 minutes after cardio pulmonary bypass, between cardio pulmonary bypass time and level of coronary sinus lactate after cross clamp release, between cardio pulmonary bypass time and level of lactate at 15 minutes after cardio pulmonary bypass, between cardio pulmonary bypass time and level of urea on the day of ICU discharge, between cardio pulmonary bypass time and level of creatinine on the day of ICU discharge,between cardio pulmonary bypass time and duration of mechanical ventilation, between cardio pulmonary bypass time and duration of ICU stay and between cardio pulmonary bypass time and duration of hospital stay.A significant positive correlation is also observed between cardio pulmonary bypass time and arrhythmia needing intervention in ICU.

Arrhythmias needing some form of intervention to treat arrhythmia, either with pacing, pacemaker or medical therapy during the whole ICU stay may be due to the variety of reasons. These group of patients had a significantly high mean cross clamp time $(121.85 \pm 25.64$ minu tes) and mean cardiopulmonary bypass time ( $169.42 \pm 45.91$ minutes ), a significantly high level of mean coronary sinus troponin $T$ after cross clamp release $(672.42 \pm 210.51 \mathrm{ng} / \mathrm{L})$ and coronary sinus troponin $\mathrm{T}$ at 15 minutes after cardio pulmonary bypass $(1569.28 \pm 452.89 \mathrm{ng} / \mathrm{L})$. Level of coronary sinus lactate after cross clamp release $(12.37 \pm 3.85 \mathrm{mmol} / \mathrm{dl})$ and level of coronary sinus lactate at 15 minutes after cardio pulmonary bypass $(13.48 \pm 4.31 \mathrm{mmol} / \mathrm{dl})$ was also significantly high. Patients being operated for a cardiac disease who have a long aortic cross clamp time and a long cardiopulmonary bypass time suffer more.Patientsneeding double valve replacement and three patients of mitral valve replacement suffered from arrhythmias necessitating intervention because of a very highaortic cross clamp time and a long cardiopulmonary bypass time. There is a significant positive correlation betweencoronary sinus troponin 
T after cross clamp release with the cross clamp time and cardio pulmonary bypass time.Existence of a significant positive correlation is also concluded between level of coronary sinus lactate after cross clamp release and arrhythmia. A significant positive correlation is also drawn between level of coronary sinus lactate after cross clamp release and cross clamp time, and cardio pulmonary bypass time. Hence this study draws an overall conclusion that lesser the aortic cross clamp time and the cardiopulmonary bypass time in cardiac surgery, lesser will be the insult to the myocardium in terms of ischemic injury and oxidative stress. The insult may be quantified with serial estimation of the markers like Troponin $T$ and Lactate through the coronary sinus which has a direct correlation with the degree of myocardial insult and hene will alert us beforehand to predict the patients who will require more attention during the perioperative period. More emphasis on the cardioprotection is the need of much attention in todays' cardiac surgical practice. Cannulation of the coronary sinus is a valuable adjunct for the study of cardiac metabolism during extracorporeal circulation and it is accomplished without complications.

\section{Declarations}

The above study is approved by the institution ethics committee of Institute of postgraduate medical education and research, Kolkata, India.

The authors declare that there is no conflict of interest for the above study.

\section{References}

1. Force T, Hibbert P, Weeks GW, Kemper AJ, Bloomfield P, Tow D, et al. Perioperative myocardial infarction after coronary artery bypass surgery: clinical significance and approach to risk stratification. Circulation 1990; 82:903-12.

2. Stiles QR, Kirklin JW. Myocardial preservation symposium. J Thorac Cardiovasc Surg 1981; 82:87082.

3. Cummins B, Auckland ML, Cummins P. Cardiac specific troponin Tradioimmunoassay in the diagnosis of acute myocardial infarction. Am Heart J 1987; 113:1333-44.

4. Wolf RE, Graeber GM, Burge JR, Deshong JL, Macdonald JL, Zajtchuk R. Evaluation of serum creatine kinase and lactate dehydrogenase in experimental myocardial infarction, atriotomies, and thoracotomies. Ann Thorac Surg 1986; 41:378-86.

5. Griesmacher A, Grimm M, Schreiner W, Muller M. Diagnosis of perioperative myocardial infarction by considering relationship of postoperative electrocardiogram changes and enzyme increases after coronary bypass operation. Clin Chem 1990; 36:883-7.

6. Munzer T, Heim C, Reisen W. Perioperative myocardial infarction and cardiac complications after noncardiac surgery in patients with prior myocardial infarction. III: Troponin T - a significant diagnostic 
alternative in perioperative myocardial infarction. Anaesthetist 1996; 45:225-30.

7. Uchino T, Belboul A, Roberts D, Jagenburg R. Measurement of myosin light chain I and troponin T as markers of myocardial damage after cardiac surgery. J Cardiovasc Surg (Torino) 1994; 35:201-6.

8. Katus HA, Remppis A, Looser S, Hallermeier K, Scheffold T, Kubler W. Enzyme-linked immunoassay of cardiac troponin T for the detection of acute myocardial infarction. J Mol Cardiol 1989; 21:1349-53.

9. Mair J, Dienstl F, Puschendorf B. Cardiac troponin T in the diagnosis of myocardial injury. Crit Rev Clin Lab Sci 1992; 29:31-57.

10. Pearlstone JR, Carpenter MR, Smillie LB. Amino acid sequence of rabbit cardiac troponin T. J Biol Chem 1986; 261:16795-810.

11. Briggs $M M$, Schachat $F$. N-terminal amino acid sequence of three functionally different troponin $T$ isoforms from rabbit fast skeletal muscle. J Mol Biol 1989; 206:245-9.

12. Cohen G, Borger MA, Weisel RD, Rao V. Intraoperative myocardial protection: current trends and future perspectives Ann Thorac Surg 1999; 68:1995-2001.

13. Yau TM, Borger MA, Weisel RD, Ivanov J. The changing pattern of reoperative coronary surgery: trends in 1230 consecutive reoperations J Thorac Cardiovasc Surg 2000; 120:156-14. Onorati F, Renzulli A, De Feo $\mathrm{M}$, et al. Does antegrade cardioplegia alone provide adequate myocardial protection in patients with left stem main disease? J Thorac Cardiovasc Surg 2003; 126:1345-1351.

15. Crittenden MD. Intraoperative metabolic monitoring of the heart: clinical assessment of coronary sinus metabolites Ann Thorac Surg 2001; 72(Suppl):2220-2226.

16. Khabbaz KR, Zankoul F, Warner KG. Intraoperative metabolic monitoring of the heart: online measurement of myocardial tissue pH Ann Thorac Surg 2001;72(Suppl):2227-2234.

17. Siouffi SY, Kwasnik EM, Khouri SF. Methods for the metabolic quantification of regional myocardial ischemia J Surg Res 1987;43:360-378.

18. Vijay P, Szekely L, Aufiero TX, Sharp TG. Coronary sinus adrenomedullin rises in response to myocardial injury Clin Sci 1999; 96:415-420.

19. Koh TW, Hooper J, Kemp M, et al. Intraoperative release of troponin I in coronary venous and arterial blood and its relation to recovery of left ventricular function and oxidative metabolism following coronary artery surgery Heart 1998;80:341-348.

20. Rao V, Ivanov J, Weisel $\mathrm{R}$, et al. Lactate release during reperfusion predicts low cardiac output syndrome after coronary bypass surgery Ann Thorac Surg 2001;71:1925-1930. 
21. NamayDL, Hammermeister KE, Zia MS,et al. (1982) Effect of perioperative myocardial infarction on late survival in patients undergoing coronary artery surgery. Circulation65:1066-1071.

22. ManganoDT(1994) Beyond CKMB.Biochemical markers for perioperative myocardial infarction. Anesthesiology 81:1317-1320.

23. KatusHA, Schoeppenthau M, Tanzeem A, et al. (1991) Non invasive assessment of perioperative myocardial cell damage by circulating cardiac troponin $\mathrm{T}$. Br Heart J65:259-264.

24. KatusHA, RemppisA, Neumann FJ, et al. (1991) Diagnostic efficiency of troponin T measurements in acutemyocardial infarction. Circulation 83:902-912.

25. JenkinsDP, PugsleyWB, Alkhulaifi AM, et al.(1997) Ischaemic preconditioning reduces troponin T release in patients undergoing coronary artery bypasssurgery. Heart77:314-318.

26. Taggart DP, Bhusari S, Hooper J, et al. (1994) Intermittent ischaemic arrest and cardioplegia in coronary artery surgery: coming a full circle? Br Heart J 72:136- 139.

27. Taggart DP, YoungV, Hooper J, et al.(1994) Lack of cardioprotective efficacy of allopurinol in coronaryarterysurgery. BrHeart J 71:177-181.

28. Boldt J, RotheG, Schindler E, et al.(1996) Can clonidine, enoximone and enalapril help protect themyocardium against ischaemia in cardiacsurgery? Heart 76:207-213.

29. T W KohJ Hooper, M Kemp, F D Ferdinand, D G Gibson, J R Pepper. Intraoperative release of troponin $\mathrm{T}$ in coronary venous and arterial blood and its relation to recovery of left ventricular function and oxidative metabolism following coronary artery surgery. Heart 1998; 80:341-348 doi:10.1136/hrt.80.4.341.

30. Francesco Onorati, $M D^{a}{ }^{a}$, Lucia Cristodoro, $M^{a}$, Santo Caroleo, $M^{b}{ }^{b}$, Antonio Esposito, $M D^{a}$, Bruno Amantea, $\mathrm{MD}^{\mathrm{b}}$, Ermenegildo Santangelo, $\mathrm{MD}^{\mathrm{b}}$,Attilio Renzulli, MD, $\mathrm{PhD}^{\mathrm{a}}$. Troponin I and Lactate From Coronary Sinus Predict Cardiac Complications After Myocardial Revascularization. Ann Thorac Surg 2007; 83:1016-1023.

31. Vivek Rao, MD, PhD' ${ }^{a}$, Joan Ivanov, RN, MSc ${ }^{a}$, Richard D. Weisel, $M D^{a}$, Gideon Cohen, MD ${ }^{a}$, Michael A. Borger, $\mathrm{MD}^{\mathrm{a}}$, Donald A.G. Mickle, $\mathrm{MD}^{\mathrm{a}}$. Lactate release during reperfusion predicts low cardiac output syndrome after coronary bypass surgery. AnnThoracSurg 2001;71:1925-1930.

32. Takayoshi Tsutamoto, Chiho Kawahara, Masayuki Yamaji, Keizo Nishiyama, Masanori Fujii, Takashi Yamamoto, and Minoru Horie Relationship between renal function and serum cardiac troponin $\mathrm{T}$ in patients with chronic heart failure. European Journal of Heart Failure (2009) 11, 653-658.

33. PiekarskaML, SzurlejB, LatusekT, WdowikG, DejaMA.Postoperative serum troponin concentration in patients undergoing aortic valve repolacemant does not predictearly postoperative outcome. Kardiol 
Pol.2013;71(12):1237-44. Doi: 10.5603/KP.a2013.0147.Epub 2013 Jun 25

34. Hernández-Romero D, Vílchez JA, Lahoz Á, et al. High-sensitivity troponin T as a biomarker for the development of atrial fibrillation after cardiac surgery. Eur J Cardiothorac Surg. 2014;45(4):733-738. doi:10.1093/ejcts/ezt488

35. Croal BL, Hillis GS, Gibson PH, et al. Relationship between postoperative cardiac troponin I levels and outcome of cardiac surgery. Circulation. 2006;114(14):1468-1475.

doi:10.1161/CIRCULATIONAHA. 105.60237

36. J L Januzzi Jr. HSR Proc Intensive Care Cardiovasc Anesth. 2009;1(3): 22- 32.PMCID: PMC3484554

37. Januzzi JL, Lewandrowski K, MacGillivray TE, Newell JB, Kathiresan S, Servoss SJ,Lee-

Lewandrowski E. A comparison of cardiac troponin T and creatine kinase-MB for patient evaluation after cardiac surgery. J Am Coll Cardiol. 2002 May 1;39(9):1518-23.

38. Lurati Buse GA, Koller MT, Grapow M, Bolliger D, Seeberger M, Filipovic M. Theprognostic valueoftroponin releaseafteradult cardiac surgery - a meta-analysis. Eur J Cardiothorac Surg. 2010 Feb;37(2):399-406. doi: 10.1016/j.ejcts.2009.05.054. Epub 2009 Aug 20.

39. Di Stefano S, Casquero E, Bustamante R, Gualis J, Carrascal Y, Bustamante J, Fulquet E, Florez S, Echevarria JR, Fiz L. Plasma troponins as markers of myocardial damage during cardiac surgery with extracorporeal circulation. Tohoku J Exp Med. 2007 Sep;213(1):63-9.

40. Kacila M, Bevilaqua S, Matteucci S, Solinas M, Farnetti A, Jacopo G, Glauber M. Inflammatory and metabolic response of the myocardium during aortic valvesurgeryon thebeatingheart. Bosn $\mathrm{J}$ Basic Med Sci. 2006 May;6(2):59-62.

41. Onorati F, Cristodoro L, Caroleo S, Esposito A, Amantea B, Santangelo E, Renzulli A. Troponin I and lactate from coronary sinus predict cardiac complications after myocardial revascularization. Ann Thorac Surg. 2007 Mar;83(3):1016-23.

42. Koh TW, Carr-White GS, DeSouza AC, Ferdinand FD, Hooper J, Kemp M, Gibson DG, Pepper JR. Intraoperative cardiac troponin $\mathrm{T}$ release and lactate metabolism duringcoronary artery surgery:comparison of beating heart with conventional coronary arterysurgerywith cardiopulmonary bypass. Heart. 1999 May;81(5):495-500.

43. Andreas Borowski, MD, Muhammed Kurt, MD, Sanchez Calvo, DSc, Gerrit Paprotny, CCP,Erhard Godehardt, DPhil,Jan Fraessdorf, MD, and Ali Ghodsizad, MD. Metabolic monitoring of postischaemic myocardium during intermittent warm blood cardioplegic administration Tex Heart InstJ. 2010;37(2): 184-188 PMCID: PMC2851414

44. Trunk P, Gersak B. Comparison of serum troponin I and plasma lactate concentrations in arrested versus beating-heart aortic valve replacement. J Heart Valve Dis. 2010 Nov;19(6):716-22. 
45.Bomfim V, Kaijser L, Olin C. Myocardial protection during aortic valve replacement. Physiological and metabolic effects of selective coronary perfusion on the fibrillating heart. Scand J Thorac Cardiovasc Surg. 1978;12(3):207-12.

46. Maillet JM, Le Besnerais P, Cantoni M, Nataf P, Ruffenach A, Lessana A, Brodaty D.Frequency, risk factors, and outcome of hyperlactatemia after cardiac surgery. Chest. 2003 May;123(5):1361-6.

47. Onorati F, Santini F, Menon T, Amoncelli E, Campanella F, Pechlivanidis K, Faggian G, Mazzucco A. Leukocyte filtration of blood cardioplegia attenuates myocardial damage and inflammation. Eur $\mathrm{J}$ Cardiothorac Surg. 2013 Jan;43(1):81-9. doi: 10.1093/ejcts/ezs145. Epub 2012 Mar 30.

48. Guillermo Mojena Morfa, MD, Julio Taín Blázquez, MD, PhD, Ángel M. Paredes Cordero, MD, Horacio Pérez López, MD, PhD, José R. Llanes Echevarría, BS, Lisbeth González González, MD A Comparison of Beating Heart and Arrested Heart Techniques for Mitral Valve Replacement Surgery. MEDICC Review, Winter 2009, Vol 11, No 1 36-41

49. Takayoshi Tsutamoto*, Chiho Kawahara, Masayuki Yamaji, Keizo Nishiyama, Masanori Fujii, Takashi Yamamoto, and Minoru Horie. Relationship between renal function and serum cardiac troponin T in patients with chronic heart failure. European Journal of Heart Failure (2009) 11, 653-658.

50. Jogia PM, Kalkoff M, Sleigh JW, Bertinelli A, La Pine M, Richards AM, Devlin G. NT-pro BNP secretion and clinical endpoints in cardiac surgeryintensive care patients. Anaesth Intensive Care. 2007 Jun;35(3):363-9.

51. PM Kapoor, B Mandal, UK Chowdhury, SP Singh, and U Kiran. J Anaesthesiol Clin Pharmacol. 2011 Apr-Jun; 27(2): 225-232.

52. Moffitt EA, Molnar GD, McGoon DC. Myocardial and body metabolism in fatal cardiogenic shock after valvular replacement. Circulation. 1971Aug;44(2):237-44.

53. Robertson I, Sun YB, MX Li, BD Sykes (2010). "A structural and functional perspective into the mechanism of $\mathrm{Ca}^{2+}$-sensitizers that target the cardiac troponin complex". Journal of Molecular and Cellular Cardiology 49: 1031-1041.

54. Moses, Marsha A.; Wiederschain D.; Wu I.; Fernandez, C.; Ghazizadeh V.; Lane W.; Flynn E.; Sytkowski A.; Tao T.; Langer R. (1999). "Troponin I is present in human cartilage and inhibits angiogenesis". Proceedings of the National Academy of Sciences of the United States of America 96 (6): 2645-2650.

55. Antman EM, Tanasijevic MJ, Thompson B, et al. (October 1996). "Cardiac-specific troponin I levels to predict the risk of mortality in patients with acute coronary syndromes". N. Engl. J. Med.335 (18): 13429. 
56. Ammann P, Pfisterer M, Fehr T, Rickli H (May 2004). "Raised cardiac troponins". BMJ 328(7447): $1028-9$

57. Tsai SH, Chu SJ, Hsu CW, Cheng SM, Yang SP (March 2008). "Use and interpretation of cardiac troponins in the ED". Am J Emerg Med 26 (3): 331-41.

58. Lim W, Qushmaq I, Devereaux PJ, et al. (2006). "Elevated cardiac troponin measurements in critically ill patients". Arch. Intern. Med. 166 (22): 2446-54.

59. Henry CR, Satran D, Lindgren B, Adkinson C, Nicholson Cl, Henry TD (January 2006). "Myocardial injury and long-term mortality following moderate to severe carbon monoxide poisoning". JAMA 295 (4): 398-402.

60. Satran D, Henry CR, Adkinson C, Nicholson Cl, Bracha Y, Henry TD (May 2005). "Cardiovascular manifestations of moderate to severe carbon monoxide poisoning". J. Am. Coll. Cardiol. 45 (9): 1513-6.

61. Bonnefoy E, Godon P, Kirkorian G, Chabaud S, Touboul P (April 2005). "Significance of serum troponin I elevation in patients with acute aortic dissection of the ascending aorta". Acta Cardiol60 (2): 165-70.

62. Needham DM, Shufelt KA, Tomlinson G, Scholey JW, Newton GE (October 2004). "Troponin I and T levels in renal failure patients without acute coronary syndrome: a systematic review of the literature". Can J Cardiol 20 (12): 1212-8.

63. Khan NA, Hemmelgarn BR, Tonelli M, Thompson CR, Levin A (November 2005). "Prognostic value of troponin T and I among asymptomatic patients with end-stage renal disease: a meta-analysis".

Circulation 112 (20): 3088-96.

64. Rifai N, Douglas PS, O'Toole M, Rimm E, Ginsburg GS (April 1999). "Cardiac troponin T and I, echocardiographic [correction of electrocardiographic] wall motion analyses, and ejection fractions in athletes participating in the Hawaii Ironman Triathlon". Am. J. Cardiol. 83 (7): 1085-9.

65. Neumayr G, Gaenzer H, Pfister R, et al. (February 2001). "Plasma levels of cardiac troponin I after prolonged strenuous endurance exercise". Am. J. Cardiol. 87 (3): 369-71, A10.doi:10.1016/S00029149(00)01382-5

66. Urhausen A, Scharhag J, Herrmann M, Kindermann W (September 2004). "Clinical significance of increased cardiac troponins T and I in participants of ultra-endurance events".Am. J. Cardiol. 94 (5): $696-$ 8.

67. Kobayashi S, Tanaka M, Tamura N, Hashimoto H, Hirose S (September 1992). "Serum cardiac troponin T in polymyositis/dermatomyositis". Lancet 340 (8821):726.

68 Erlacher P, Lercher A, Falkensammer J, et al. (April 2001). "Cardiac troponin and beta- 
type myosin heavy chain concentrations in patients with polymyositis or dermatomyositis". Clin. Chim. Acta 306 (1-2): 27-33

69 Fleming SM, O'Gorman T, Finn J, Grimes H, Daly K, Morrison JJ (November 2000). "Cardiac troponin I in pre-eclampsia and gestational hypertension". BJOG 107(11): 1417-20.

70 Morton A (July 2004). "Raised cardiac troponins: troponin is raised in pre-eclampsia". BMJ329 (7457): 111.

71 Gaze DC,Collinson PO; Collinson, PO (December 2005). "Cardiac troponins as biomarkers of drug- and toxin-induced cardiac toxicity and cardioprotection.". Expert Opin Drug Metab Toxicol. 1 (4): 715-25.

72. Melanson SE, Tanasijevic MJ, Jarolim P (October 2007). "Cardiac troponin assays: a view from the clinical chemistry laboratory". Circulation 116 (18): e501-4.

73. Collinson PO, Boa FG, Gaze DC (September 2001). "Measurement of cardiac troponins".Ann. Clin. Biochem. 38 (Pt 5): 423-49.

74. Zethelius $B$, Johnston $N$, Venge $P$ (February 2006). "Troponin I as a predictor of coronary heart disease and mortality in 70-year-old men: a community-based cohort study". Circulation113 (8): 1071-8.

75. Willott RH, Gomes AV, Chang AN, Parvatiyar MS, Pinto JR, Potter JD (May 2010). "Mutations in Troponin that cause HCM, DCM AND RCM: what can we learn about thin filament function?". J. Mol. Cell. Cardiol. 48 (5): 882-92.

76. Myocardial lactate metabolism: evidence of lactate release during net chemical extraction in man. Gertz, E.W., Wisneski, J.A., Neese, R., Bristow, J.D., Searle, G.L., Hanlon, J.T. Circulation (1981.

\section{Figures}




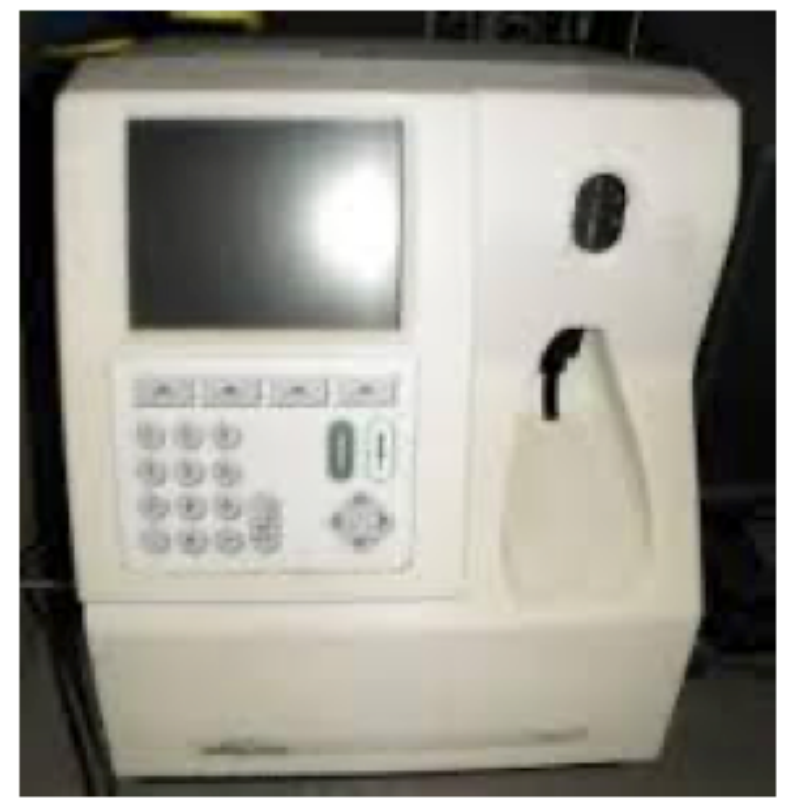

Figure 1

NOVA PHOX Blood Gas Analyser.

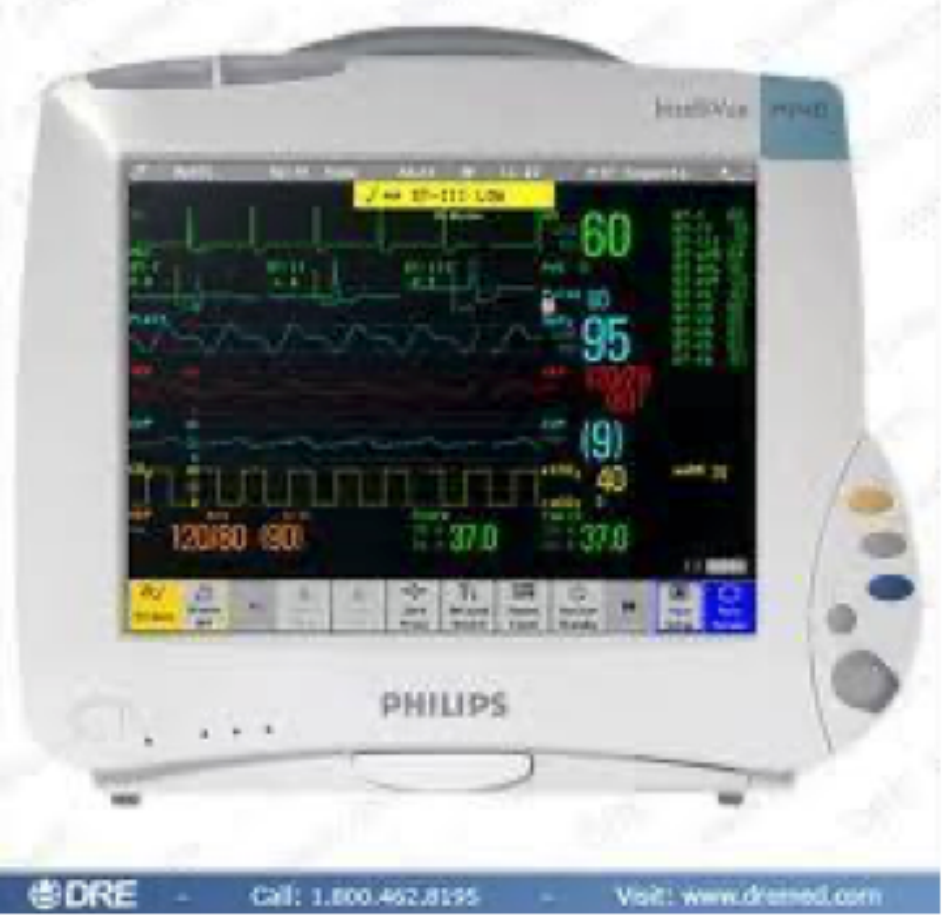

Figure 2

IntelliVue MP20 patient monitor. 


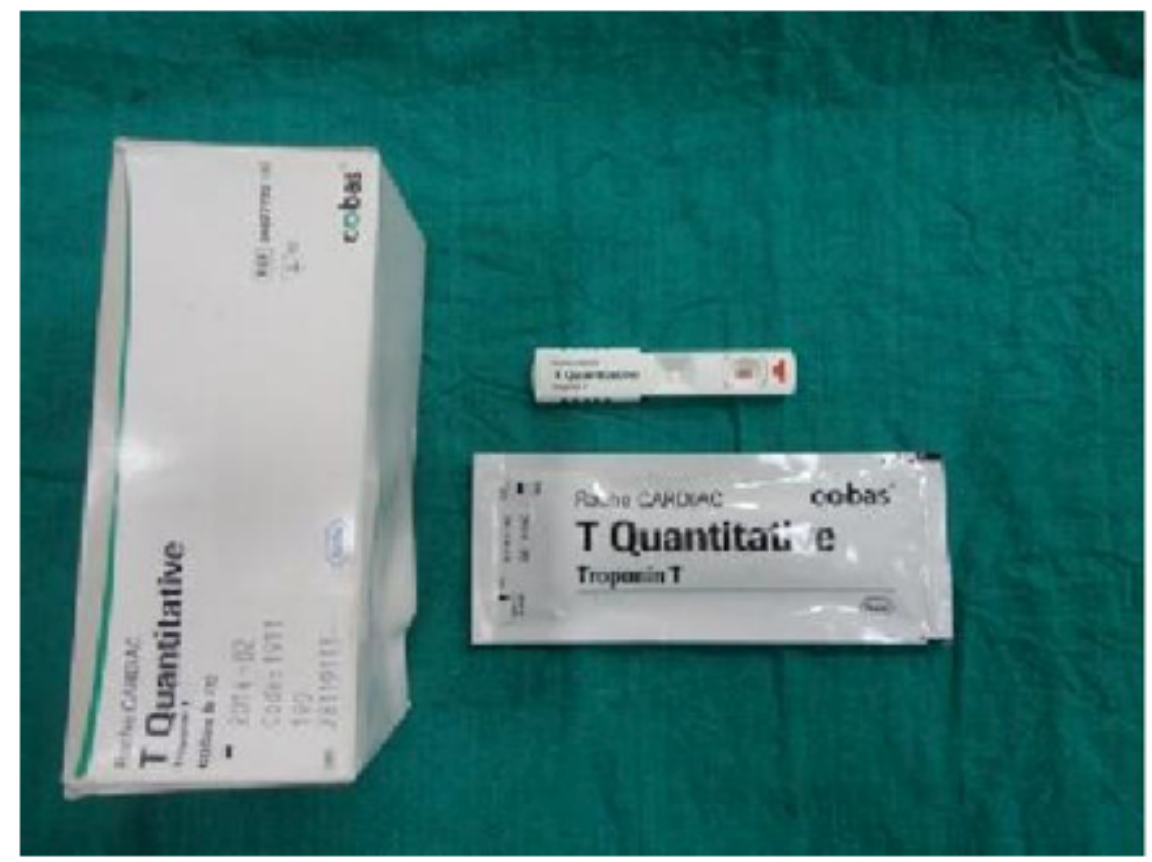

Figure 3

Roche CARDIAC T Quantitative cassette

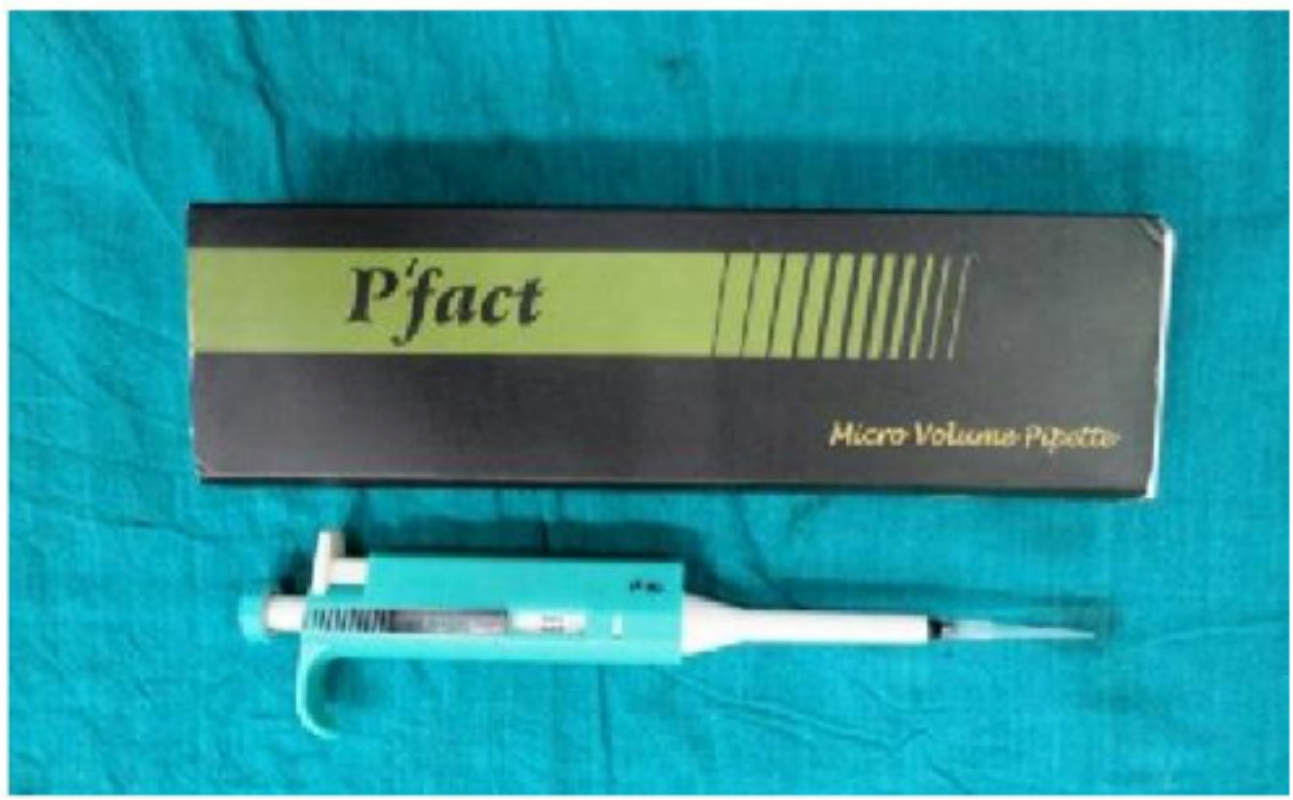

Figure 4

Micorpipette. 


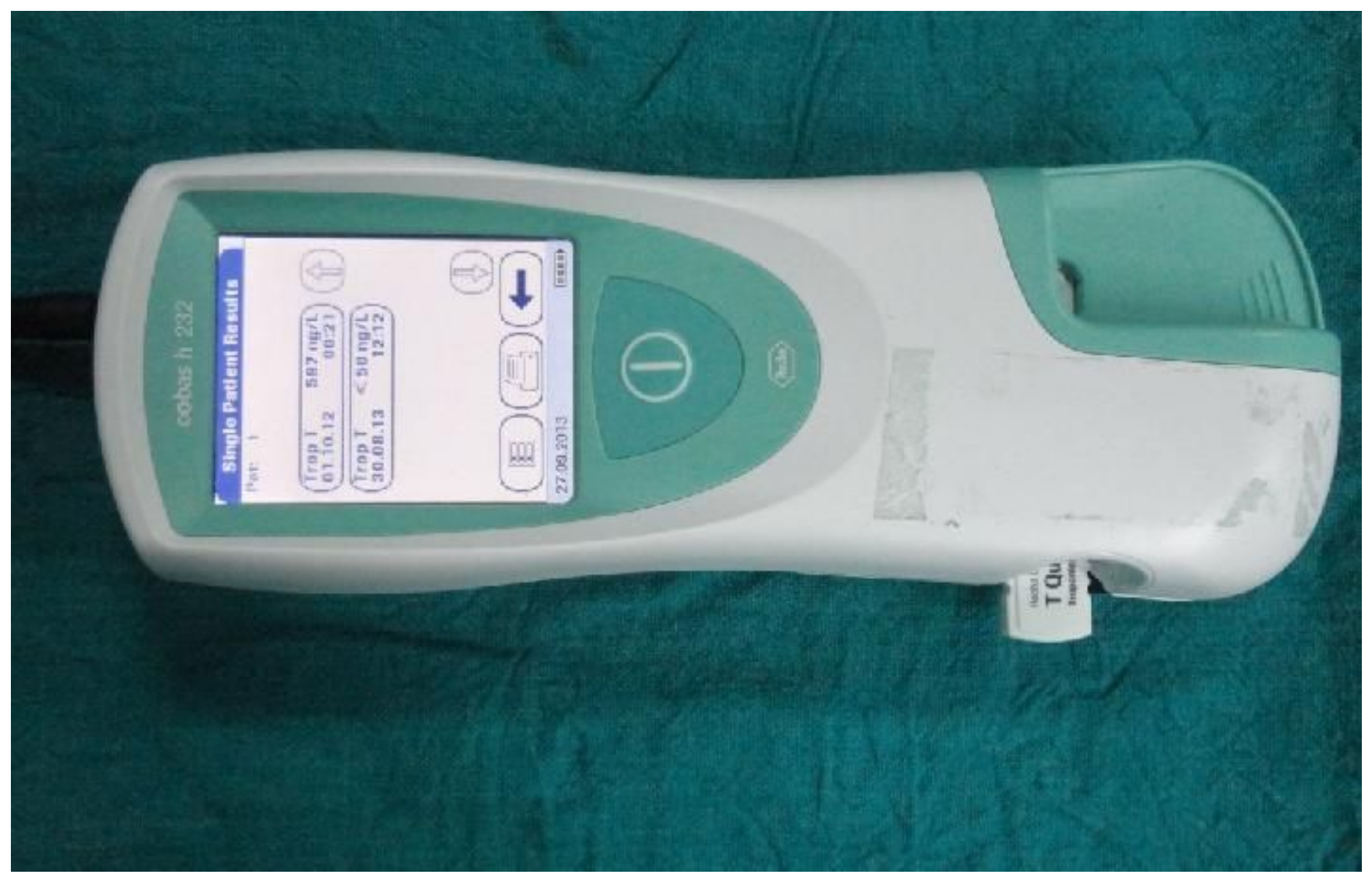

\section{Figure 5}

Cobas h 232 Troponin T portable analyser machine. 


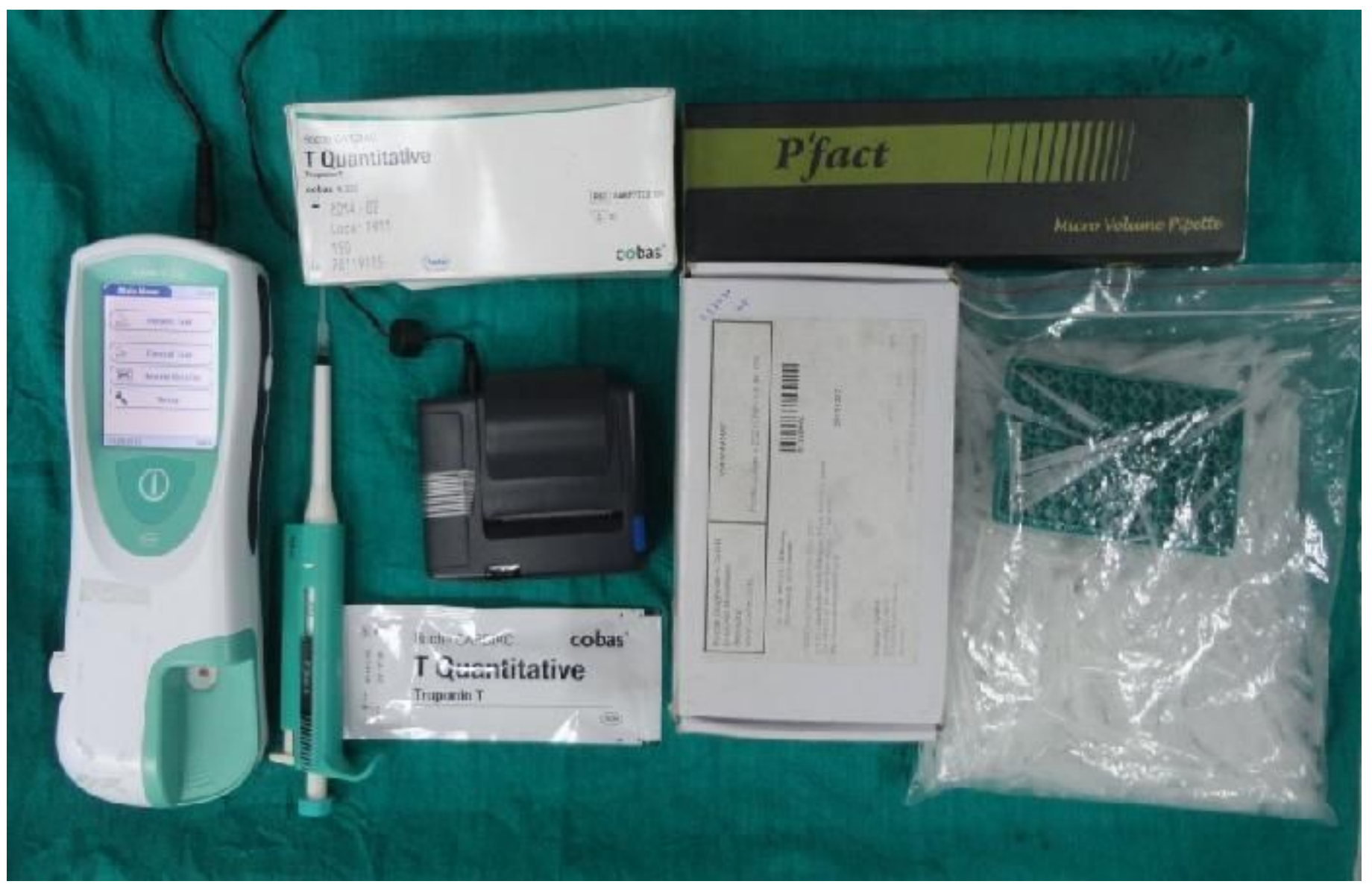

Figure 6

Cobas h 232 Troponin T kit.

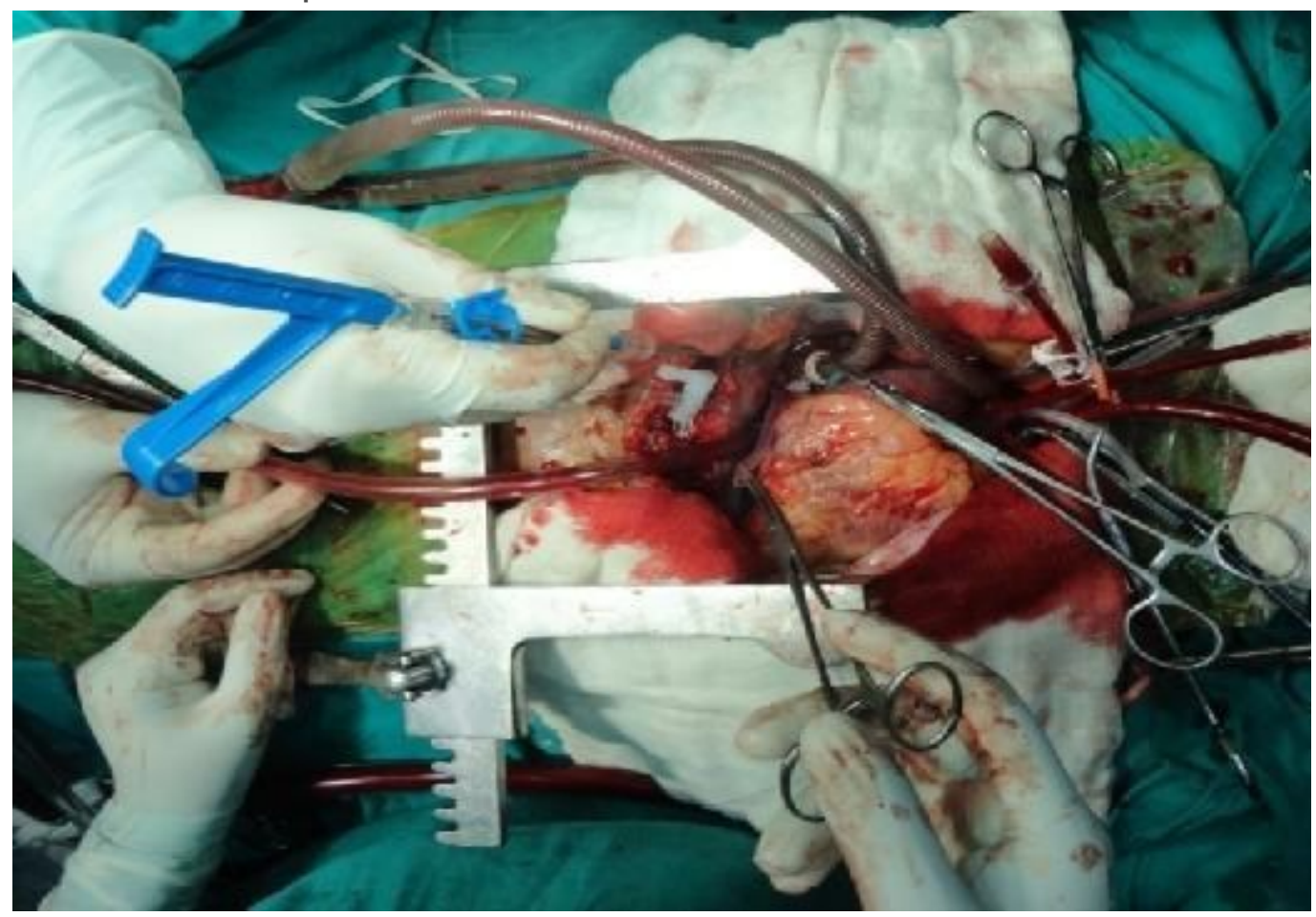

Figure 7 
Retrograde cardioplegia cannula insertion technique.

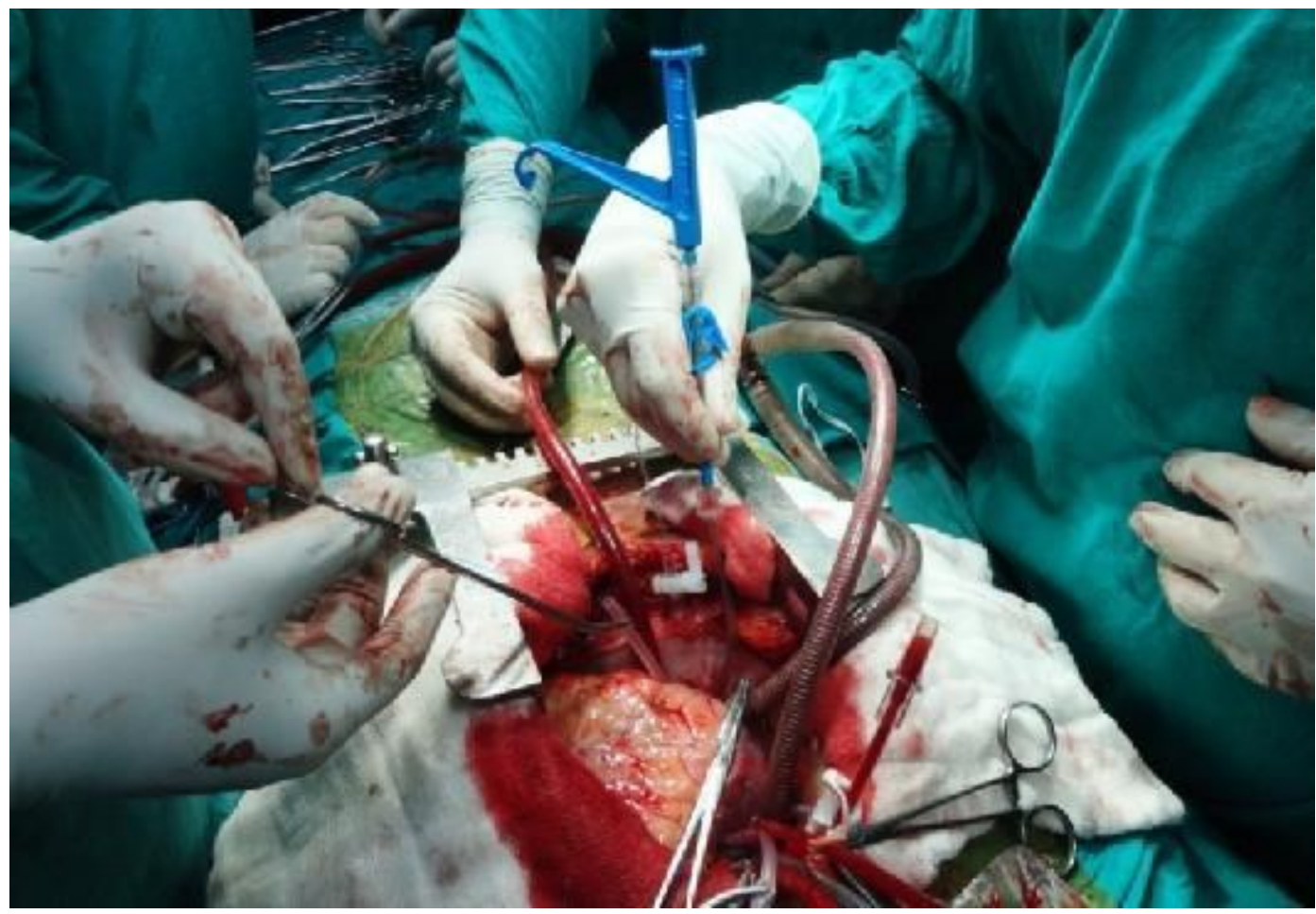

Figure 8

Retrograde cardioplegia cannula insertion technique

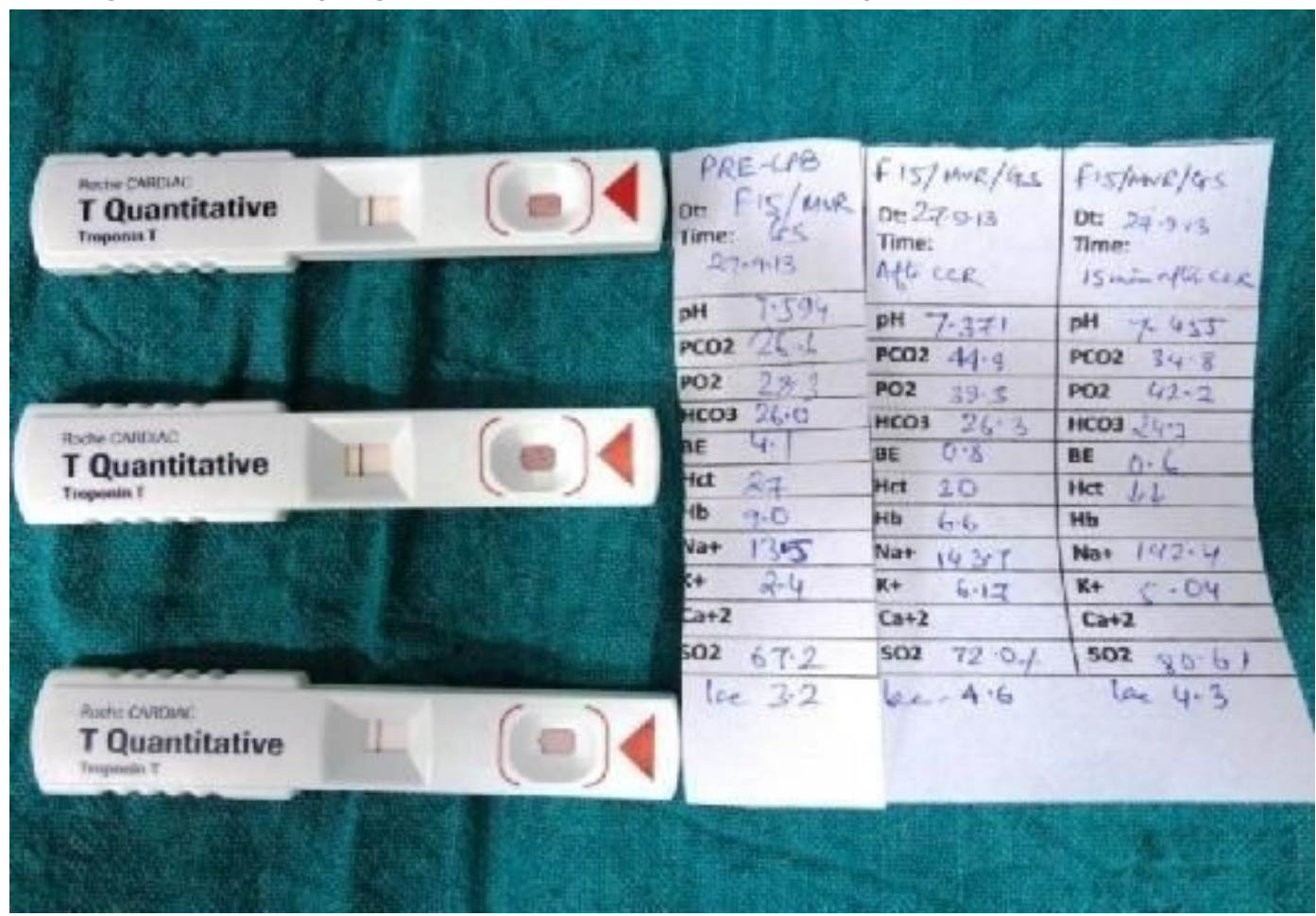

Figure 9

Troponin T kits; The NOVA PHOX analysis result for lactate 